\title{
Lightweighting Shipping Containers: Life Cycle Impacts on Multimodal Freight Transportation
}

\author{
by
}

Cailin A. Buchanan

\author{
A thesis submitted in partial \\ fulfillment of the requirements for the \\ degree of Masters of Science \\ (Environment and Sustainability) in \\ the University of Michigan
}

August 2018

\section{Thesis Committee:}

Professor Gregory A. Keoleian, Chair

Research Specialist Geoffrey M. Lewis

Research Specialist John L. Sullivan 



\section{Acknowledgements}

I would like to thank Professor Gregory Keoleian and Research Specialists John Sullivan and Geoff Lewis for sharing their expertise related to life cycle assessment, lightweighting, and the transportation system in general throughout this project. Their constant guidance and weekly meetings ensured that this research project was on track and ultimately successful. Additionally, their sound counsel on matters as far ranging as $\mathrm{PhD}$ programs and travel in Ireland were very much appreciated. It has been an honor to work with all three of these experts. I would also like to thank my fellow graduate student Marwan Charara for his work on the shipping container model and paper we published related to this study. Without his involvement, the study would not have been nearly as comprehensive.

This research was conducted through Lightweight Innovations for Tomorrow (LIFT), a collaboration between universities and private industries to promote the development of lightweight materials manufacturing technologies. This work was directly supported by ALMMII (American Lightweight Materials Manufacturing Innovation Institute), which is sponsored by the U.S. Navy's Office of Naval Research (Cooperative Agreement Number N00014-14-2-0002 issued by the U.S. Department of Defense). In addition, I wish to acknowledge the following for their helpful contributions: Alan Taub for his technical and practical comments, Matt Collette for sharing his detailed knowledge of the shipping industry, Adithya Dahagama for his descriptions of marine ports, Krutarth Jhaveri for his weekly feedback, Soren Johannsen for his container expertise, and Randy Stiefel, Paul Weidenfeller, Brian Slack, and Helaine Hunscher for their support throughout the course of the work. I would also like to thank my parents for their support and advice throughout my graduate school experience. 


\section{Preface}

This thesis is an exploratory study conducted through Lightweight Innovations for Tomorrow (LIFT) to investigate the energy consumed and greenhouse gases emitted during the multimodal life cycle of a shipping container as well as the potential reductions in environmental burdens for six container lightweighting scenarios. The burdens and savings are reported first for a single shipping container, and then are scaled up to indicate the savings possible if all shipping containers were lightweighted first in the United States and then globally. Additionally, a case study is conducted to examine the environmental burdens associated with several routes possible for the transportation of shipping containers from Shanghai to Detroit, Michigan. This thesis highlights the tradeoff between fuel savings incurred through lightweighting and potential increased production burdens associated with some of the lightweighting strategies. Furthermore, it indicates the influential nature of modal distribution and route selection on life cycle results and demonstrates a specific use of multimodal modeling that could be replicated and applied to other transportation systems.

The work presented in this thesis has been recently published in the journal Transportation Research Part D: Transport and the Environment: Buchanan, C. A., Charara, M., Sullivan, J. L., Lewis, G. M., and Keoleian, G. A. (2018). Lightweighting shipping containers: Life cycle impacts on multimodal freight transportation. Transportation Research Part D, 62, 418-432. https://doi.org/10.1016/j.trd.2018.03.011. The thesis contains additional detail related to the methods used. 


\section{Contents}

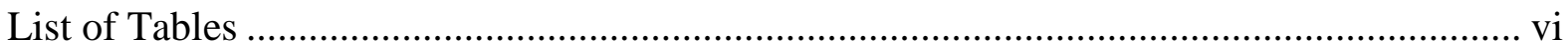

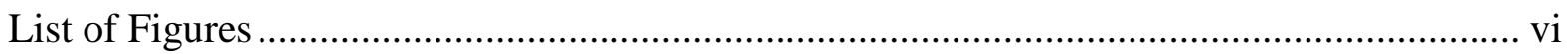

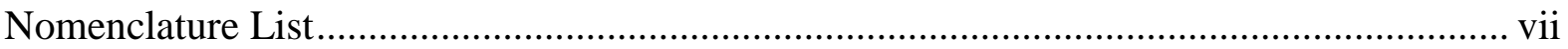

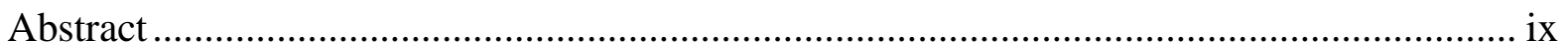

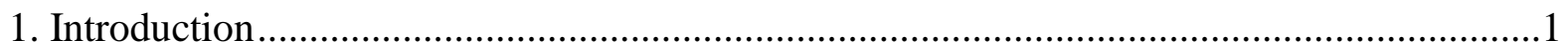

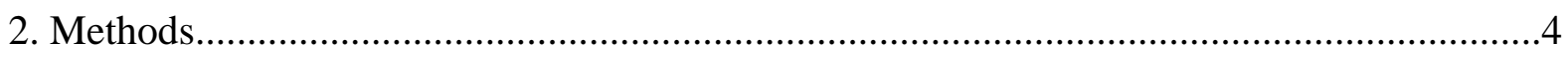

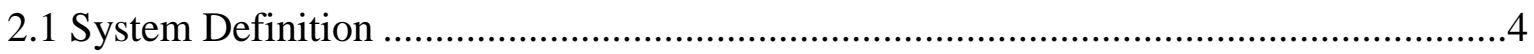

2.2 Container Life Cycle Analysis ...............................................................................6

2.3 National and Global Level Analysis ..........................................................................15

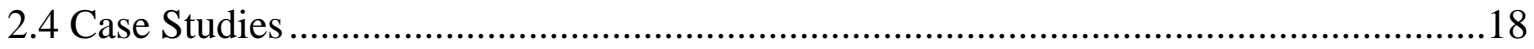

2.4.1 Far East - North America: Shanghai to Detroit......................................................19

2.4.2 Europe - North America: Rotterdam to Pittsburgh ..............................................20

2.5 Uncertainty Analysis: Monte Carlo Simulations ………………………………….....20

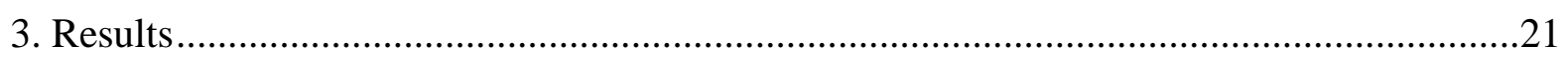

3.1 Container Burdens and Savings ………………………........................................21

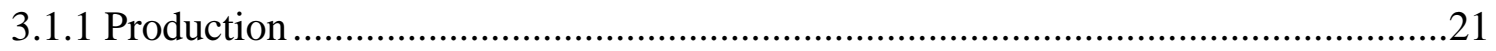

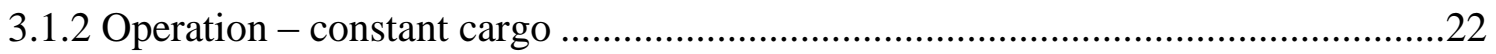

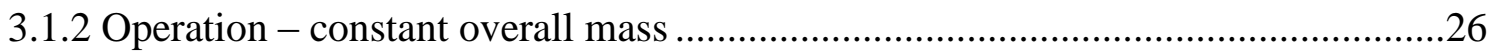

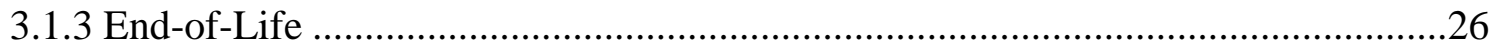

3.1.4 Life Cycle

3.2 National and Global Level Burdens and Savings ……………………....................29

3.2.1 National Savings (Truck and Train) ………………...........................................29

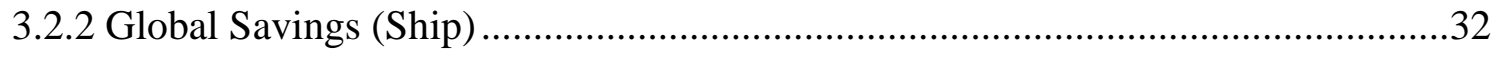

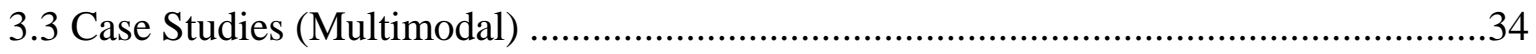




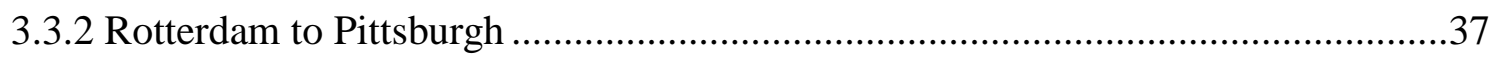

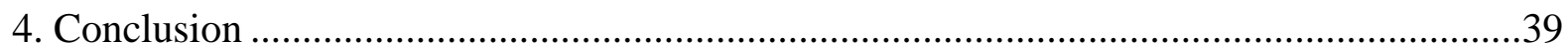

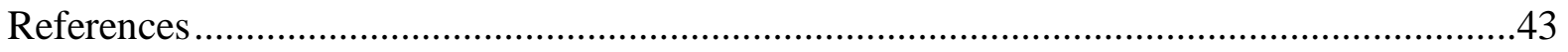

Appendix A: Supplemental Information ................................................................48

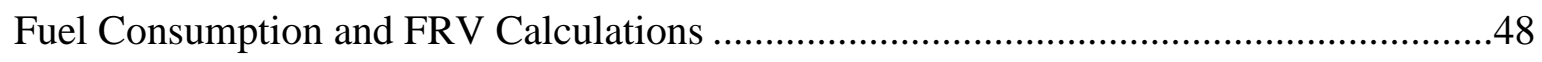

Uncertainty Analysis: Monte Carlo Analysis ..............................................................54 


\section{List of Tables}

Table 1: Material inventory for production of one conventional 40 foot shipping container 7

Table 2: Chemical Composition of Corten steel (in \%) ..............................................8

Table 3: Chemical Composition of High Tensile Steel (in \%) .....................................8

Table 4: Specifications for truck, train, and ship freight modes used ............................12

Table 5: The distance traveled by container ships on each trading route .........................17

Table A1: Vehicle specifics, fuel consumption, fuel intensity, and FRVs for a wide range of vehicles ................................................................................................48

Table A2: Percent fuel savings for a $1 \%$ change in hull mass for a variety of ship capacities (ABS, 2013)...................................................................................52

Table A3: Input values with common uncertainty values in all case studies ....................62

\section{List of Figures}

Figure 1 Single Container Fuel Consumption.................................................23

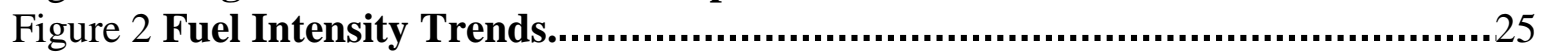

Figure 3 Single Container Life Cycle Energy Demand......................................28

Figure 4 U.S. Container Fleet Life Cycle Energy Demand......................................30

Figure 5 Global Container Fleet Life Cycle Energy Demand...................................33

Figure A1 Monte Carlo Single Container Fuel Consumption................................55

Figure A2 Monte Carlo Single Container Life Cycle Energy Demand......................57

Figure A3 Monte Carlo U.S. Container Fleet Life Cycle Energy Demand..................59

Figure A4 Monte Carlo Global Container Fleet Life Cycle Energy Demand............. 61

Figure A5 Monte Carlo Shanghai to Detroit (West) Case Study Energy Demand......63

Figure A6 Monte Carlo Shanghai to Detroit (Easy) Case Study Energy Demand...... 65

Figure A7 Monte Carlo Rotterdam to Pittsburgh (No Backhauling) Case Study

Energy Demand...............................................................................................66

Figure A8 Monte Carlo Rotterdam to Pittsburgh (Backhauling) Case Study

Energy Demand. 


\section{Nomenclature List}

A Rolling resistance (journal bearing, rolling, and track resistances)

a Acceleration

B Higher order rolling resistance and mechanical rotational losses (flange friction, flange impact, rail rolling friction)

C Aerodynamic losses (head wind pressure, rear drag, skin resistance, and yaw angle of wind tunnels)

$D_{\text {all vessels }} \quad$ Total distance traveled by all vessels on route

$D_{\text {haul } \quad \text { Average trip distance per haul }}$

Dst Duty cycle distance

$D_{\text {total }} \quad$ Distance one ship travels on route

FC Overall fuel consumption

$F C_{a c c} \quad$ Fuel consumption driven by accessory loading

$F C_{\text {aero }} \quad$ Fuel consumption driven by aerodynamic resistance

$F C_{\text {conv }} \quad$ Fuel consumption of a conventional vehicle

$F C_{f} \quad$ Fuel consumption driven by mechanical losses due to engine friction and pumping

$F C_{\text {full }} \quad$ Fuel consumption for a fully loaded container

$F C_{l} \quad$ Fuel consumption driven by miscellaneous powertrain losses

$F C_{L W} \quad$ Fuel consumption of a lightweighted vehicle

$F C_{M} \quad$ Fuel consumption driven by the transportation of mass

$F C_{7 M T} \quad$ Fuel consumption for a container loaded to 7 metric tons on a truck or train

FRV Fuel Reduction Value

$H_{f} \quad$ Fuel lower heating value

$M \quad$ Mass 


$\begin{array}{cl}M_{\text {full }} & \text { Mass of a fully loaded container } \\ M_{7 M T} & \text { Mass of a container loaded to } 7 \text { metric tons on a truck or train } \\ N_{\text {hauls }} & \text { Number of hauls } \\ \eta_{i} & \text { Engine efficiency } \\ \eta_{t} & \text { Transmissions efficiency } \\ N_{v e s s e l s} & \text { Number of vessels on shipping route } \\ \mathrm{R} & \text { Train running resistance } \\ S_{c r u i s i n g} & \text { Cruising speed of a ship } \\ t & \text { Time } \\ T_{h a u l} & \text { Total time needed in hours to complete a haul } \\ v & \text { Speed of vehicle } \\ \gamma & \text { All non-mass related terms }\end{array}$




\section{Abstract}

Freight transportation by truck, train, and ship accounts for 5\% of the United States' annual energy consumption (U.S. Energy Information Administration, 2017a). Much of this freight is transported in shipping containers. Lightweighting containers is an unexplored strategy to decrease energy and GHG emissions. We evaluate life cycle fuel savings and environmental performance of lightweighting scenarios applied to a forty-foot container transported by ship, train, and truck. Use phase burdens for both conventional and lightweighted containers (steel reduction, substitution with aluminum, or substitution with high tensile steel) were compared to life cycle burdens. The study scope ranged from the transportation of one container $100 \mathrm{~km}$ to the lifetime movement of the global container fleet on ships. Case studies demonstrated the impact of lightweighting on typical multimodal freight deliveries to the United States. GREET (Argonne National Laboratory, 2017) was used to estimate the total fuel cycle burdens associated with use phase fuel consumption. Fuel consumption was determined using modal Fuel Reduction Values (FRV), which relate mass reduction to fuel reduction. A lifetime reduction of $21 \%$ in the fuel required to transport a container, and $1.4 \%$ in the total fuel required to move the vehicles, cargo, and containers can be achieved. It was determined that a $10 \%$ reduction in mass of the system will result in a fuel reduction ranging from $2 \%$ to $8.4 \%$, depending on the mode. Globally, container lightweighting can reduce energy demand by 3.6 EJ and GHG emissions by 300 million tonnes $\mathrm{CO}_{2}$ e over a 15 -year lifetime. 


\section{Introduction}

The transportation sector accounted for $29 \%$ of the United States' energy consumption in 2016 (U.S. Energy Information Administration, 2017a), with truck, train, and ship freight movement accounting for over $20 \%$ of this consumption (28 quads). Freight transportation relies primarily on fossil fuels, resulting in release of greenhouse gases (GHG), which are known for their negative environmental effects (Davis et al., 2016; Ramanathan and Feng, 2009; U.S. EPA, 2017). Lightweighting offers an opportunity to reduce fuel, energy, and emissions during transportation, as the lighter the vessel, the less fuel required to move it. $90 \%$ of non-bulk cargo worldwide is transported by containers, with the total world container fleet estimated at 35 million TEU (Twenty-foot Equivalent Units) (Castonguay, 2009; Theofanis and Boile, 2009). The potential savings that can be achieved through lightweighting are significant, since a large amount of fuel is required to transport containers over their lifetimes.

The goal of this study was to model the life cycle reduction in energy, and GHG emissions that are possible by lightweighting shipping containers. Fuel savings implications were examined for both the U.S. and global container fleets, as well as two typical multimodal trips.

U.S. government agencies regularly collect data on energy and emissions from the freight transportation sector including GHG inventories by economic sector, transportation-specific information such as modal energy intensity, and annual freight transportation energy demand and emissions, broken down by mode and fuel types (Davis et al., 2016; U.S. DOT, 2017; U.S. EPA, 2015). Many studies that model energy demand base estimates of freight transportation energy consumption on national tonne-km data, or use these as an input to predictive models (Pietzcker et al., 2014; Ramanathan, 2000; Schipper et al., 1997; Zhang et al., 2009). Cargo volume can also be used to model energy demand, generally in the form of TEU or TEU-mile 
(Winebrake et al., 2008). These cargo-related metrics will not demonstrate the impact of container mass on fuel consumption, so instead of basing calculations on national energy demand, the impacts of lightweighting need to be calculated for an individual container, and then scaled up to estimate the nationwide effect of lightweighting.

Energy intensity is a metric used to allocate on a unit mass basis the energy consumed to transport a payload. An example set of units is liters of fuel/100 tonne-km. When transporting people, liters/passenger-km is used. Analysis of energy intensity trends can be used to estimate future consumption. Energy intensity studies are in agreement that trucks are the most energy intensive mode. Modal distribution and vehicle and cargo mass influence intensity, as increased truck mode share increases intensity, and increased cargo mass decreases intensity (Kamakaté \& Schipper, 2009; McKinnon, 1999). Chester and Horvath demonstrated the influence of total mass on energy and emission intensity for a high-speed passenger train, noting that higher occupancy results in lower energy intensity (Chester \& Horvath, 2010). Recent energy intensity research has focused primarily on the truck mode, so work on other modes is necessary to ensure a more comprehensive understanding of modal energy intensities.

Lightweighting is an approach with potential to reduce freight transportation energy and emissions. Multiple studies have identified lightweighting strategies for freight transportation, with an emphasis on the truck mode, most likely due to its relatively higher energy intensity. These studies indicate that fuel savings can range from 6 to $20 \%$ based on the lightweighting strategy employed and the mode considered (Ang-Olson and Schroeer, 2002; Galos et al., 2015; Hubbard and Beck, 2016; Odhams et al., 2010; Prucz et al., 2013; U.S. EPA, 2016). Some studies model fuel consumption based on anticipated drive cycles (Galos et al., 2015; Odhams et al., 2010). This is a better approach for estimating fuel savings from mass reduction 
than simply using a rule-of-thumb estimation, because it also accounts for other, non-mass related components such as aerodynamic drag and friction. Fuel consumption models can be used to estimate a modal Fuel Reduction Value (FRV). This quantity estimates the reduction in fuel use resulting from a vehicle mass reduction and has been extensively studied for cars and light duty trucks (Kim et al., 2015; Kim and Wallington, 2013). The use of fuel consumption models to derive an FRV is an innovative development in the estimation of fuel savings, as in the past, fuel demand for the freight sector is based on aggregate tonne-kilometer data. FRVs also enable a bottom-up calculation approach, in which we estimate the potential fuel, energy and emissions savings that are achievable through the lightweighting of a single shipping container, and then scale up the savings to represent the savings possible if we lightweight all containers in the United States or globally.

Life Cycle Assessment (LCA) is used to assess the environmental impacts of a product or system over its full life cycle, from material production and manufacturing, through use to endof-life. The International Organization for Standardization (ISO) details the principles and framework for LCA in ISO 14040 (ISO, 2006). Identified issues with LCA include data uncertainty, modeling issues, and weighting (Finnveden et al., 2009; Hellweg and Milà i Canals, 2014; Pennington et al., 2004). Despite these challenges, LCA provides a holistic accounting of burdens, and is thus a valuable tool to use when assessing the impact of a product. There are many examples of life cycle assessments for freight transportation modes (Bachmann et al., 2015; Facanha and Horvath, 2007; Nahlik et al., 2016; Schipper et al., 1997; Spielmann and Scholz, 2005). The consensus is that road freight is the least energy efficient and releases the most emissions per unit cargo mass (Facanha and Horvath, 2007; Nahlik et al., 2016; Schipper et al., 1997; Spielmann and Scholz, 2005). Fuel mix as well as modal shifts 
directly impact quantity of emissions in a freight transport system (Schipper et al., 1997). Most work has not included intermodal combinations of freight transportation, is regionally specific, or is dated. LCAs that analyze the effect of lightweighting aircraft, electric vehicles, and freight trucks have also been conducted, demonstrating the potential trade-off between increased manufacturing burdens and decreased mass leading to lower operational burdens (Scelsi et al., 2011; Zanchi et al., 2016). Aircraft containers have been a target for lightweighting applications, however published research related specifically to lightweighting shipping containers is rare (Helms and Lambrecht, 2004; Prucz et al., 2013). This paper describes a contribution to this field of study. The approach used here to model the impact of lightweighting for freight transportation was based on the use of FRV to relate the mass of a vehicle directly to its fuel consumption. Based on shipping container lightweighting and the resulting fuel savings, the reduction in energy demand and GHG emissions were quantified for several lightweighting scenarios. The lightweighting scenarios included thinning the steel gauge of the nonstructural components of the container (panels and roof) by 10 and 20\%, reducing the mass of all of the steel in the container, including structural components by 10 and 20\%, and material substitution with both High Tensile Steel (HTS) and aluminum. These lightweighting scenarios will be defined in greater detail in Section 2.1.

\section{Methods}

\subsection{System Definition}

The container modeled was 40 feet long with a height of 8.5 feet and width of 8 feet (2 TEU)

(Descalle et al., 2006). The mass of a container was approximately $3,690 \mathrm{~kg}(2,900 \mathrm{~kg}$ of Corten A steel, $15 \mathrm{~kg}$ of stainless steel, $178 \mathrm{~kg}$ of mild steel, $589 \mathrm{~kg}$ of plywood, $8 \mathrm{~kg}$ of 
rubber), which aligned with literature values (DSV, n.d.; Steinecker Containerhandel, 2012). Modes considered were a Kenworth T660 Class 8 Line Haul truck with a Cummins ISX 14.9L engine (Delorme et al., 2009), and a freight train with a 40 CFR 1033.53 duty cycle (Sullivan et al., 2018), which both used conventional diesel fuel (43.4 MJ/L), and a 4,500 TEU Panamax container ship, which used residual fuel oil (45.4 MJ/L). The container ship dimensions, deadweight, and displacement were averaged from a Panamax ship and a Neopanamax ship, which both carried the desired capacity of 4,500 TEU (ABS, 2013). Fuel data, including heating values and densities, as well as burdens associated with upstream processes and combustion, were obtained from GREET 1 (Argonne National Laboratory, 2016a). We assumed that the truck carries one container, the train carries 200 (two per flat car), and that the ship was the most common size currently in use, with a capacity of 4,500 TEU or 2,250 forty foot containers (Alphaliner, 2016). While the three major modes were considered, intermodal transportation, or the movement of the containers from one mode to another via cranes, tractors, and rubber tired gantry (RTG), was less than $0.02 \%$ of a container's life cycle energy and emissions and was not considered in this study (A Dahagama 2017, personal communication, 21 August, Port Houston).

Six lightweighting scenarios were investigated. Lightweight material substitution scenarios typically focus on the tradeoff between higher material production burdens for the lighter material and lower operational burdens resulting from the lighter material. The first two scenarios consisted of lightweighting the Corten A steel wall and roof panels by $10 \%$ and $20 \%$, resulting in mass reductions of $175 \mathrm{~kg}$ and $351 \mathrm{~kg}$, respectively. The second two scenarios consisted of lightweighting all the steel in the container (including structural components) by $10 \%$ and $20 \%$, resulting in mass reductions of $309 \mathrm{~kg}$ and $618 \mathrm{~kg}$, 
respectively. Manufacturing processes are the same as for a conventional container in these four lightweighting scenarios. In the fifth scenario, approximately 3 tonnes of Corten A steel were replaced with 2.6 tonnes of High Tensile Steel (HTS). In the final scenario, 1.8 tonnes of Corten A steel used for the wall and roof panels were replaced with approximately $960 \mathrm{~kg}$ of aluminum, assuming the structural integrity will not be affected and that dissimilar materials can be joined effectively without compromising the lifetime or function of the container.

The act of lightweighting can spur further opportunities for lightweighting, which is called secondary lightweighting. This occurs because supporting vehicle parts, such as load-bearing structural components or even the vehicle powertrain, now require less material and or power themselves in order to support the lightweighted vehicle, or in this case, container. Assuming that a mass limited container will only have more mass added to it when it is lightweighted, secondary lightweighting generally should only be considered for a volume limited container, in which more weight cannot be added to the system. While this is an important area of research, secondary lightweighting is not considered in this project because whether a container is mass or volume limited is circumstantial, and so it cannot be assumed that a container will always be volume limited.

\subsection{Container Life Cycle Analysis}

LCA accounts for burdens in material production, manufacturing, use, and end-of-life stages, and adds them together to estimate impacts over the full life cycle. The following section will outline the data sources and calculations of the burdens and savings associated with lightweighting a container in each of its life cycle phases (Sections 2.2.1-2.2.3), and then will 
discuss the assumptions necessary to determine the burdens over a container's entire lifetime (Section 2.2.4).

\subsubsection{Production Burdens}

Burdens associated with container production result from material production, manufacturing (stamping, roll forming, galvanization, etc.), and assembly (welding, priming, painting, etc.). Table 1 below is the material inventory for a forty-foot container, determined through a standard shipping container inventory list (Steinecker Containerhandel, 2012).

Table 1: Material inventory for production of one conventional 40 foot shipping container.

\begin{tabular}{lrc}
\hline \multicolumn{1}{c}{ Material } & Mass $(\mathbf{k g})$ & $\begin{array}{c}\text { Mass Percent Composition } \\
(\mathbf{\%})\end{array}$ \\
\hline Steel & & \\
$\quad$ Corten A & 2,899 & 78.6 \\
$\quad$ Stainless & 15 & 0.4 \\
$\quad$ Mild/Carbon & 178 & 4.8 \\
Plywood & 589 & 16.0 \\
Rubber & 8 & 0.2 \\
\hline Total & $\mathbf{3 , 6 8 9}$ & $\mathbf{1 0 0 . 0}$ \\
\hline
\end{tabular}

From the material inventory, material flows required could be determined for each production and manufacturing phase, depending on scrap rates for that particular process. Scrap rates for the manufacturing processes were assumed to be $1 \%$ or less. A sensitivity analysis was performed in which scrap rates were varied from zero to $10 \%$. A $10 \%$ scrap rate increased total container life cycle energy demand by only $0.87 \%$, demonstrating that our scrap rate assumptions did not significantly impact the results. GREET 2 (Argonne National Laboratory, $2016 \mathrm{~b})$ was used to determine energy $(\mathrm{MJ} / \mathrm{kg})$ and emission $\left(\mathrm{kg} \mathrm{CO}_{2} \mathrm{e} / \mathrm{kg}\right)$ burdens for most material production and manufacturing processes based on the amount of material required for 
each process. The energy burdens associated with the production of Corten A steel on a mass basis were not available in GREET 2, so GREET.net software was used to modify the existing steel to represent the chemical composition of Corten A steel, which is represented below in Table 2 (Argonne National Laboratory, 2017). It should be noted that sulfur data were not available in GREET, and so sulfur was neglected in the modified steel process.

Table 2: Chemical Composition of Corten steel (in mass \%)

\begin{tabular}{cccccccccc}
\hline & Fe & C & Si & Mn & P & S & Cu & Ni & Cr \\
\hline Corten & 95.98 & 0.12 & 0.75 & 0.5 & 0.15 & 0.05 & 0.55 & 0.65 & 1.25 \\
\hline
\end{tabular}

The chemical composition of steel had to similarly be adjusted for the lightweighting case where Corten is replaced by HTS. The composition of HTS is presented in Table 3 below.

Table 3: Chemical Composition of High Tensile Steel (in mass \%)

\begin{tabular}{cccccccccc}
\hline & Fe & Al & Si & Mn & P & Cu & Ni & Cr & Ti \\
\hline HTS & 96.88 & 0.015 & 0.5 & 1.6 & 0.035 & 0.35 & 0.4 & 0.2 & 0.02 \\
\hline
\end{tabular}

Burdens associated with plywood production (Athena Sustainable Materials Institute, 2012), container welding (Finkbeiner et al., 2015), and priming and painting were gathered from other sources (National Renewable Energy Laboratory, 2005, 2004, 2000). Since door hardware, plywood, and sealant installation, as well as waterproofing and degreasing processes were expected to be small and common between a traditional container and a lightweighted container, these burdens were neglected. 
After calculating the reduction in material flow for any of the lightweighting cases described in Section 2.1, new energy and GHG burdens were calculated using the same method as described above for the conventional container. The reduction in production burdens from lightweighting the container was then obtained simply by comparing the burdens for the conventional container to the lightweighted version. The results of this process will be presented and discussed in Section 3.

\subsubsection{Use Burdens}

\section{Volume vs. Mass Limited Assumption}

Burdens and potential savings during operation were investigated by considering the amount of fuel used for transporting the container by each mode. There were two likely assumptions for how cargo could be treated in response to lightweighting. If the container was volumelimited, then lightweighting the container resulted in no additional cargo, because the container volume remained constant. In this constant cargo assumption, overall mass was reduced, and energy burdens and GHG emissions were expected to decrease. Fuel intensity was also expected to decrease, because the amount of fuel required to move the mass of the container was decreasing. It is these savings that are compared to total life cycle burdens of a conventional container in Section 3. If the container was mass-limited, lightweighting resulted in additional cargo, up to the mass limit of the container. This constant overall mass assumption resulted in no total fuel savings, as the same overall mass was transported, though there was a reduction in fuel intensity. These results will also be presented in Section 3. 


\section{Fuel Reduction Values of Vehicles}

The effect of container lightweighting on fuel consumption was estimated with FRVs. For any given mode of transportation, the FRV quantifies the incremental effect of a change in the vehicle's overall mass on its fuel consumption, in units of volume of fuel per unit distance per unit mass, as shown in Equation 1, where $F C$ is fuel consumption per $100 \mathrm{~km}$ (for both conventional and lightweight scenarios), $\Delta M$ is change in mass, and $F R V$ is the fuel reduction value for the vehicle being considered. FRV can be defined by Equation 2 .

$$
\begin{array}{cc}
F C_{L W}=F C_{\text {conv }}-\Delta M \times F R V & \text { Eq. } 1 \\
F R V=\frac{\Delta F C}{\Delta M} & \text { Eq. } 2
\end{array}
$$

For truck and train (and all wheeled vehicles), a linear relationship exists between mass and fuel consumption. The relationship between fuel consumption and mass for ships is complicated and hence, simple expressions for that dependence are not available. While the amount of a ship's wetted surface is responsible for both frictional and wave making resistances to motion, it is dependent on ship displacement (total mass) and hull shape. Changes in ship mass, all other dependences held constant, yield changes in ship draft, which is non-linearly related to the amount of ship surface beneath the water. The ship FRVs employed in our study were computed using data from an ABS study where lightship masses were reduced while at the same time ship block coefficients were adjusted so as to maintain constant deadweight. Nevertheless, we take these FRVs as approximate and use them only for incremental mass changes. 


\section{Fuel Consumption and Burden Calculations}

To calculate modal environmental burdens, typical FCs and FRVs for truck and train were obtained from work conducted by Sullivan et al. (2018b). Ship fuel consumption and FRV were calculated based on data provided in an ABS report (2013). For a more detailed description of the methods used to determine the fuel consumption and FRV for conventionally weighted trucks, trains, and ships, please refer to Appendix A. Fuel consumption and FRV for the three modes used are collected in Table 4. While the maximum payload for each container is 20.6 tonnes, it was assumed in our calculations that the container was loaded to an average of 7 tonnes, because the average density of a shipping container ranges from 6-8 pounds per cubic foot (uShip, 2015), so the cargo of a forty-foot container with a volume of 2,720 cubic feet weighs between 6.5-8.7 tonnes. Thus the truck and the train were assumed to have containers loaded to 7 tonnes. The ship data provided in the ABS report was for a ship loaded to 7 tonnes/TEU (14 tonnes/forty-foot container) (ABS, 2013). This affects the design draft and thus the expected fuel consumption. For the purpose of this study, it was assumed that ships with containers loaded only to 7 tonnes would add ballast to bring the ship to the design draft of the ship as reported by ABS. Thus in Table 4, ship fuel consumption is the same as it would be for ABS conditions, in which twenty-foot containers are loaded to 7 tonnes. The truck and train values for $\mathrm{M}_{\text {vehicle }}$ was obtained from Sullivan et al. (2018b), and the $\mathrm{M}_{\text {vehicle }}$ value for the ship was the averaged value for two Panamax ships, as reported by ABS (2013). Payload mass, $\mathrm{M}_{\mathrm{pyld}}$, was calculated for each of the vehicles by multiplying the number of containers by 7 tonnes, and the mass of the gross vehicle, $\mathrm{Mgv}_{\mathrm{gv}}$, was calculated by summing $\mathrm{M}_{\text {vehicle }}$ and $\mathrm{M}_{\mathrm{pyld}}$. 
Table 4: Specifications for truck, train, and ship freight modes used

\begin{tabular}{lcccccc}
\hline & $\mathrm{M}_{\text {vehicle }}$ & Number of & $\mathrm{M}_{\text {pyld }}$ & $\mathrm{M}_{\mathrm{gv}}$ & $\mathrm{FC}$ & FRV \\
& (tonnes) & Containers & (tonnes) & (tonnes) & $(L / 100 \mathrm{~km})$ & $($ L/100 tonne- $k m)$ \\
\hline Truck & $15.7^{\mathrm{a}}$ & 1 & 7.0 & 22.7 & 36.8 & 0.617 \\
Train & $2,788^{\mathrm{a}}$ & 200 & 1,400 & 4,188 & 1,484 & 0.117 \\
Ship & $49,695^{\mathrm{b}}$ & 2,250 & 15,750 & 65,445 & 13,999 & 0.179 \\
\hline
\end{tabular}

${ }^{a}$ This mass includes the mass of the container(s)

${ }^{\mathrm{b}}$ This mass includes the mass of the containers as well as the mass of the fuel, water, ballast, crew, stores, passengers, etc.

Using these fuel consumption values and life cycle fuel data from GREET 1, energy demand and GHG emissions (per $100 \mathrm{~km}$ ) for the total life cycle of the fuel were calculated for all scenarios (Argonne National Laboratory, 2016a). Fuel consumption was divided by cargo mass to calculate fuel intensity for both cargo scenarios.

\subsubsection{End-of-Life Burdens}

The container consists of three main materials: steel (Corten, mild, stainless), plywood, and rubber. As previously indicated in Table 1, steel makes up $83.7 \%$ of the container by mass with Corten being the major component (94\%). In addition, a shipping container is made from $16.1 \%$ plywood and $0.2 \%$ rubber by mass. Plywood attracts insects, and for it to last over the container's lifetime and sustain the harsh conditions that the container is exposed to it has to be treated with pesticides and other chemicals. For this reason, all plywood and rubber are assumed to go to landfill, and only the steel is being recycled. Typically, most steel is $100 \%$ recyclable, and can be used repeatedly though perhaps not for the same applications (Bureau of International Recycling, 2017). Steel has a high economic value, and its versatility enables it to be easily recycled and remanufactured according to demand. In addition, its magnetic property makes it easy to separate from other types of waste. 
There are two approaches to modeling end-of-life of metals in life cycle assessment: the recycled content approach and the end-of-life recycling approach (Frischknecht, 2010). The former applies no recycling credits whereas the latter applies credits for the mass of materials recycled. This study used the recycled content approach, which accounts for the environmental impacts of metals at the time they occur and gives no credits for recycling the metals in the future. In the recycled content approach, it is assumed that when a product- in this case the container- is at its end of life phase, it is dismantled and then goes through a shredder where it is turned into scrap (U.S. Automotive Materials Partnership et al., 1999). This process has a burden associated with it that is denoted $\{B\}_{E O L}$. Once the metal is shredded it has to be transported, cleaned, and beneficiated to improve its quality and composition before it goes into the scrap pool. The collection of burdens from all the aforementioned processes is denoted $\{B\}_{S 1}$. Any scrap used in the feedstock of the production of new containers - or any steel products for that matter - is drawn from this scrap pool, and transported to the smelting facility. The burdens for the transportation process is denoted $\{B\}_{S 2}$. Typically any new steel that is being produced has a recycled content that ranges from $25-35 \%$, with the rest being virgin steel (Argonne National Laboratory, 2016a). Letting that virgin content be denoted $f$ and using the recycled content approach, the burdens of producing new steel $\{B\}_{N E W}$ can then be computed with Equation 3 below.

$$
f\{B\}_{p}+(1-f)\{B\}_{s}=\{B\}_{N E W}
$$

In this equation, $\{B\}_{p}$ is the burden associated with the production of virgin materials and $\{B\}_{S}$ is the sum of secondary burdens $\{B\}_{S 1}$ and $\{B\}_{S 2}$. End-of-life burdens for each part of the container were calculated by multiplying the parts' masses and the energy and GHG emissions 
associated with transporting, disassembling, and shredding, acquired from literature (U.S. Automotive Materials Partnership et al., 1999).

\subsubsection{Life Cycle Burdens}

The lifetime burdens of the operational stage were calculated by estimating annual modal distance and container lifetime. The average lifespan of a container is 15 years ( $\mathrm{S}$ Johannsen 2017, personal communication, 10 April, Maersk Container Industry), and in an average year a container travels approximately 72,405 km by truck (American Trucking Association, 2017), $37,055 \mathrm{~km}$ by train (Davis et al., 2016), and 280,094 km by ship. To determine the annual distance traveled by a container on a ship, the average distance per haul traveled by a ship along the two major shipping routes terminating in North America (Far East - North America and Europe - North America) were first determined. These two shipping routes were considered because they account for most of the United States' foreign trade (U.S. Army Corps of Engineers, 2016; U.S. Maritime Administration, 2015; UNCTAD, 2015). As demonstrated in Equation 4, once the average trip distance per haul ( $D_{\text {haul }}$ ) was determined, the total time needed to complete the haul in hours ( $\mathrm{T}_{\text {haul }}$ ) was determined by dividing by an assumed cruising speed ( $\mathrm{S}_{\text {cruising }}$ ) of 20 knots. A speed of 20 knots was used because recently observed trends in the shipping industry indicate that ships are traveling at slower speeds to conserve fuel (Meyer et al., 2012). Given the large distances container ships travel at sea, the bulk of a ship's travel will be at cruising speed, and so only cruising speed was considered in this study.

$$
T_{\text {haul }}\left(\frac{\mathrm{hr}}{\text { haul }}\right)=\frac{D_{\text {haul }}\left(\frac{\mathrm{km}}{\text { haul }}\right)}{S_{\text {cruising }}(\text { knots }) \times \frac{1.852 \mathrm{~km} / \mathrm{hr}}{\text { knots }}}
$$

Eq. 4 
After determining average time per haul, the time a vessel spends at port (Slack et al., 2017) was added to determine the total number of hours a ship would spend en-route and at port. Based on this value, the number of hauls that could be completed per year per route was determined, as demonstrated in Equation 5, where $N_{\text {hauls }}$ refers to the number of hauls.

$$
\frac{N_{\text {hauls }}}{\text { year }}=\frac{365 \text { days }}{\text { year } \times T_{\text {haul }}\left(\frac{h r}{\text { haul }}\right)} \times \frac{24 h r}{d a y}
$$

The distance that a ship could presumably travel per year on one of these routes could then be calculated simply by multiplying the distance per haul by the number of hauls. The number of vessels on each route (Alphaliner, 2016) was then used to determine total distance traveled by all ships on that route, as demonstrated in Equation 6, where $D_{\text {all vessels }}$ represents the total distance traveled by all ships on a route, $N_{\text {vessels }}$ refers to the number of vessels on each of the routes, and $D_{\text {total }}$ refers to the distance one ship could travel on that route.

$$
D_{\text {all vessels }}=N_{\text {vessels }} * \frac{D_{\text {total }}}{\text { vessel }}
$$

Finally, the distance traveled by all ships for the two routes were summed together and the total number of ships on the two routes was divided out from this total distance to determine an average annual distance that could be traveled by a ship on these routes.

\subsection{National and Global Level Analysis}

Fuel savings achieved through lightweighting were scaled up to estimate the potential impact lightweighting could have at national and global scales. A ratio of national to global traffic (flow of cargo measured in TEU) and global fleet size were used to determine the approximate number of shipping containers in the United States, as demonstrated by Equation 7. The burdens per container-km were then multiplied by the number of containers and expected 
lifetime distances of truck and train transport in the United States to calculate the overall national burdens. These burdens accounted for transport of shipping containers by truck and train modes within the U.S. only.

$$
\frac{U S_{\text {fleet }}}{U S_{\text {traffic }}}=\frac{\text { World }_{\text {fleet }}}{\text { World }_{\text {traffic }}}
$$

To compute the savings achieved through lightweighting all containers transported on ships globally, the average distance traveled by a ship was calculated based on the distances of each of the relevant shipping routes, the number of vessels that travel on each route, the major trading partners for each area, the time a vessel spends at each port (Appendix D), and the cruising speed of a ship, which is assumed to be 20 knots. All data can be found in Table 5 .

From this data, the average annual distance traveled by a container ship on all trading routes is $248,000 \mathrm{~km}$, or 3.7 million $\mathrm{km}$ in 15 years. This distance was then used, along with the world container fleet (34.5 million TEU or 17.5 million 40' containers) to compute the environmental burdens associated with the global container shipping industry. 
Table 5: The distance traveled by container ships on each trading route

\begin{tabular}{|c|c|c|c|c|c|c|c|c|}
\hline Route & $\begin{array}{c}\text { Average } \\
\text { Distance } \\
(\mathbf{k m})\end{array}$ & $\begin{array}{c}\text { Travel } \\
\text { time } \\
(\text { hr })\end{array}$ & $\begin{array}{l}\text { Time } \\
\text { in } \\
\text { port } \\
\text { (hr) }\end{array}$ & $\begin{array}{c}\text { Overall } \\
\text { time per } \\
\text { haul } \\
\text { (hr) }\end{array}$ & $\begin{array}{c}\text { Hauls } \\
\text { per } \\
\text { year }\end{array}$ & $\begin{array}{l}\text { Distance } \\
\text { per year } \\
\left(\mathbf{1 0}^{3} \mathbf{~ k m}\right)\end{array}$ & $\begin{array}{l}\text { Vessel } \\
\text { Count }\end{array}$ & $\begin{array}{c}\text { Distance } \\
\text { by all } \\
\text { ships } \\
\left(\mathbf{1 0}^{6} \mathrm{~km}\right)\end{array}$ \\
\hline $\begin{array}{l}\text { Europe - } \\
\text { North } \\
\text { America }\end{array}$ & 6,186 & 159 & 51 & 210 & 42 & 259 & 158 & 41 \\
\hline $\begin{array}{l}\text { Far East - } \\
\text { North } \\
\text { America }\end{array}$ & 13,947 & 359 & 61 & 420 & 21 & 291 & 450 & 131 \\
\hline $\begin{array}{l}\text { Far East - } \\
\text { Europe }\end{array}$ & 17,791 & 457 & 44 & 502 & 17 & 311 & 336 & 104 \\
\hline $\begin{array}{l}\text { Middle } \\
\text { East / } \\
\text { ISC } \\
\text { related }\end{array}$ & 11,449 & 294 & 44 & 338 & 26 & 296 & 596 & 177 \\
\hline $\begin{array}{l}\text { Africa } \\
\text { related }\end{array}$ & 13,289 & 342 & 60 & 401 & 22 & 290 & 456 & 132 \\
\hline $\begin{array}{l}\text { Latin } \\
\text { America } \\
\text { related }\end{array}$ & 13,950 & 359 & 49 & 408 & 21 & 300 & 625 & 187 \\
\hline $\begin{array}{l}\text { Oceania } \\
\text { related }\end{array}$ & 8,865 & 228 & 44 & 272 & 32 & 286 & 231 & 66 \\
\hline $\begin{array}{l}\text { Intra Far } \\
\text { East }\end{array}$ & 3,108 & 80 & 44 & 124 & 71 & 220 & 1744 & 384 \\
\hline $\begin{array}{l}\text { Intra } \\
\text { Europe }\end{array}$ & 800 & 21 & 47 & 67 & 130 & 104 & 583 & 61 \\
\hline
\end{tabular}




\subsection{Case Studies}

It is useful to conduct case studies demonstrating freight transport to, from, and within the United States. The two most prevalent shipping routes for the U.S. are Far East - North America (24 million TEU per year) and Europe - North America (10 million TEU per year), so two cases will be presented that focus on these routes (UNCTAD, 2015). The case studies were used to illustrate important elements of the freight shipping industry, including the tradeoffs between transporting via ship versus rail, shipping to the east coast of the U.S. versus the west, and backhauling of empty containers.

To calculate operational burdens associated with each of the cases, distances traveled by ship were ascertained through Voyage Planner (MarineTraffic, 2017). The train and truck distances were estimated through GoogleMaps by specifying the arrival and departure locations and allowing the software to determine the most direct route. It has been determined that the truck is most cost effective when transporting freight for distances of $750 \mathrm{~km}$ or less, whereas train is more cost efficient over $750 \mathrm{~km}$ (Rodrigue et al., 2017). A similar point exists between rail and ship at approximately 1,500 km (Rodrigue et al., 2017). Distances were multiplied by the respective modal container burdens (per $100 \mathrm{~km}$ ) to obtain the total burdens associated with the entire shipping system (container, cargo, and vehicle). Production and end-of-life burdens for the container were allocated based on the total trip distance traveled compared to total lifetime distance of a container estimated above.

Time was another important factor to compare between cases, so each mode's time-in-transit were considered. An estimated ship travel time was estimated by using Sea-Distances for each case, with an average speed of 20 knots, which is a typical slow-steaming speed (Meyer et al., 2012; Sea-Distances, 2017). The average time a container spends at port before being 
transported either by truck or train was based on a study that reported the average vessel turnaround times for 70 ports (Slack et al., 2017). The time to travel by truck and rail were both estimated from distance traveled and average speed. Assuming the train travels at $50 \mathrm{mph}$ (American Association of State Highway and Transportation Officials, 2002), and doesn't make any stops, the time to travel by train was calculated by dividing the distance traveled by the speed. The same method was used to calculate container time spent on a truck, assuming the average speed of a truck is $55 \mathrm{mph}$ (Office of Energy Efficiency \& Renewable Energy, 2011).

\subsubsection{Far East - North America: Shanghai to Detroit}

Shanghai, China, the world's largest port in terms of TEUs processed (World Shipping Council, 2017a), was selected as the origin port for the first case. The purpose of this case was to compare delivery to the west coast to delivery through the Panama Canal to the east coast as well as to assess the multimodal transportation of a container. The west coast port selected was Los Angeles, CA, as it is ranked as the largest port in the United States (Burnson, 2012), while Newark, NJ was selected as it is the largest east coast port (Burnson, 2012). The final destination of Detroit, MI implies a longer inland leg - via either truck or train - via the west coast delivery route. It was assumed that after delivery to Los Angeles, the container would be transported to Chicago, IL by rail, as it is a major Midwest rail hub and the distance is greater than $750 \mathrm{~km}$. The container would then be trucked to Detroit. As the train distance is over $1,500 \mathrm{~km}$, it might actually be more efficient for a ship to travel through the Panama Canal and

deliver freight to the east coast. For the east coast route, cargo was transported to Detroit by train after being delivered by ship to Newark, NJ. 


\subsubsection{Europe - North America: Rotterdam to Pittsburgh}

The biggest Northern European port is Rotterdam in the Netherlands (World Shipping Council, 2017a). The purpose of this case, in addition to modeling a typical multimodal freight transportation route of ship to truck to final destination, was to demonstrate the effect of backhauling. This case study modeled the burdens associated with transporting a container full of cargo from Rotterdam to Newark/New York by ship, and then by truck to Pittsburgh, Pennsylvania, a representative Midwestern U.S. manufacturing city. Initially backhauling was not considered, however, the burdens are then compared to a case where the transportation of an empty container from Pittsburgh to the closest port (Baltimore, MD) by truck and then back to Rotterdam by ship was modeled.

\subsection{Uncertainty Analysis: Monte Carlo Simulations}

There is a fair amount of uncertainty in modal FRVs, lifetime distances, and fleet sizes, and this variability can influence the results dramatically. The values used throughout this report were selected based on a thorough review of literature and data; however, there are a range of values presented in the literature, from which uncertainty arises. To evaluate the effect of variability in these input parameters, a Monte Carlo sensitivity analysis was conducted on the five main analyses: modal fuel consumption, single container life cycle burdens, U.S. container fleet life cycle burdens, global container fleet life cycle burdens, and case studies. For each input with uncertainty (modal FRVs, lifetime distances, and fleet sizes), 10,000 samples were randomly selected from a triangular distribution. Results for each lightweighting scenario were calculated using the 10,000 randomly generated input values, and distributions were determined for each set of results. The specific parameter ranges and Monte Carlo simulation process are fully described in Appendix A. 


\section{Results}

The following sections will focus on the effects of lightweighting on fuel consumption as well as life cycle environmental burdens (energy and GHG emissions) at a variety of scales, beginning with a single container and scaling up to the global container fleet. It is important to note that fuel consumption results from the operation stage, while life cycle environmental flows are summed over the production, operation, and end-of-life stages. It is expected, however, that energy and emissions will be primarily driven by the combustion of fuel in the operation stage. Additionally, there are two types of fuel used in the operation stage: diesel fuel for truck and train, and residual fuel oil for ship.

\subsection{Container Burdens and Savings}

\subsubsection{Production}

As discussed in the Methods section, energy and GHG emissions associated with the production of one shipping container were calculated for a conventional container as well as for each of the six lightweighting scenarios. We determined that $123 \mathrm{GJ}$ of energy are required to produce a conventional container, and that 11 tonnes $\mathrm{CO}_{2} \mathrm{e}$ of $\mathrm{GHG}$ emissions would be released. Five of the lightweighting scenarios resulted in a reduction in production stage environmental burdens - lightweighting all of the container's steel by $20 \%$ achieved the largest reduction of $18 \%$, requiring $100 \mathrm{GJ}$ of energy and releasing 9 tonnes $\mathrm{CO}_{2} \mathrm{e}$ of GHG. Replacing the wall panels and roof with aluminum increased the environmental burdens by $64 \%$ (203 GJ of energy, 14 tonnes $\mathrm{CO}_{2} \mathrm{e}$ ) due to the increased material production burden of aluminum over steel. 


\subsubsection{Operation - constant cargo}

Fuel is consumed to move the container, the cargo, and the vehicle itself, as well as to overcome vehicle friction, aerodynamic drag, and internal powertrain friction. Since the container is only a fraction of the total mass transported, it follows that the fuel required to transport the mass of the container is a fraction of the fuel consumed to transport the total mass of the vehicle, container, and cargo. Lightweighting the container results in a reduction in fuel consumption from that fraction. Assuming constant cargo, the container was lightweighted while the cargo mass was unchanged. Overall mass of the loaded vehicle decreased, leading to savings in fuel, energy, and GHG emissions and improved fuel intensity. Based on modal FRVs and the container mass for each of the six lightweighting scenarios, fuel consumption per 100 kilometers for the conventional and lightweighted scenarios were calculated assuming constant cargo, and are presented in Figure 1. The error bars in Figure 1 illustrate the uncertainty in FC for each lightweighting scenario and mode. Based on uncertainty in the modal FRV, the modal fuel consumption can vary. The effect of parameter uncertainty was estimated through Monte Carlo simulations, and the error bars indicate a 95\% empirical prediction interval. This interval ranges from the $2.5^{\text {th }}$ percentile at the bottom of the error bar to the $97.5^{\text {th }}$ percentile at the top. The 95\% prediction interval arises from the specified input distribution and demonstrates the expected range in fuel consumption (95\% of the time). It is apparent from the asymmetric nature of the error bars that the triangular distribution of the input range was not centered on the values we used for our deterministic model. Information regarding uncertainty analysis inputs and data analysis is included in Appendix A.

The most fuel consuming mode to move a given mass of cargo was truck, as even for the greatest lightweighting scenarios (20\% all steel and replacement with aluminum), fuel 


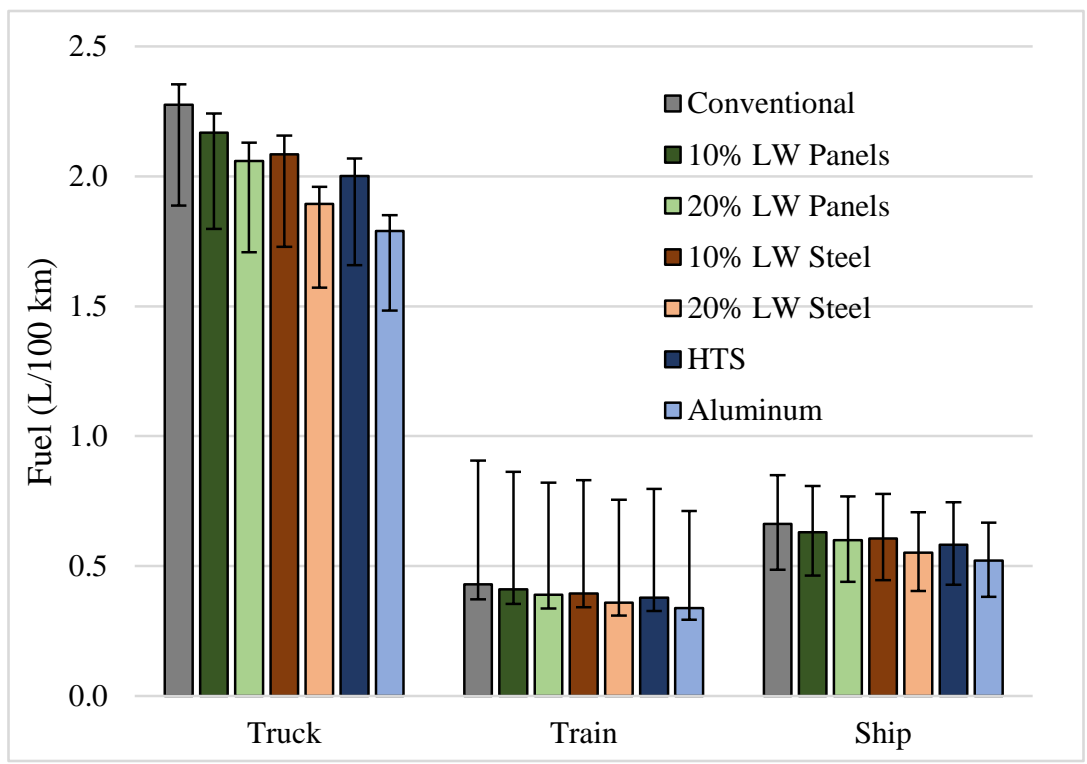

Figure 1 Single Container Fuel Consumption. Container share of fuel consumption, conventional or LW, for truck (diesel), train (diesel), and ship (residual oil), each over $100 \mathrm{~km}$, assuming constant cargo. The error bars indicate the range within which fuel consumption is expected to fall 95\% of the time, based on uncertainty in FRV. The same sets of randomized values for FRV and lifetime distances were used for each LW scenario.

Therefore, different lightweighting scenarios should be compared at the same percentile.

consumed was between 1.8 and $1.9 \mathrm{~L}$ diesel fuel $/ 100 \mathrm{~km}$, as compared to $0.34-0.36 \mathrm{~L}$ diesel fuel $/ 100 \mathrm{~km}$ for train and $0.52-0.55 \mathrm{~L}$ residual fuel oil $/ 100 \mathrm{~km}$ for ship. This has important implications for policy, because it demonstrates that the largest potential saving can be achieved by lightweighting containers that will be transported on trucks. Total fuel consumption was larger for the train and ship because of the number of containers these vehicles carry, but was smaller on a per container basis. Cumulative energy demand and GHG emissions follow the same trend as fuel consumption. The energy demand by mode was 99 $\mathrm{MJ} / 100 \mathrm{~km}$ for truck, $19 \mathrm{MJ} / 100 \mathrm{~km}$ for train, and $30 \mathrm{MJ} / 100 \mathrm{~km}$ for ship. In terms of emissions, the truck released $7.7 \mathrm{~kg} \mathrm{CO}_{2}$ e to move one container $100 \mathrm{~km}$, the train emitted 1.5 $\mathrm{kg} \mathrm{CO} 2$ e per container per $100 \mathrm{~km}$, and the ship emitted $2.5 \mathrm{~kg} \mathrm{CO}_{2} \mathrm{e}$ per container per $100 \mathrm{~km}$. The lightweighting scenario that was the most effective at reducing environmental burdens was replacing the walls and roof with aluminum, achieving a $21 \%$ reduction in energy demand 
and GHG emissions released to move the container $1 \mathrm{~km}$ by truck, train, and ship each $(3 \mathrm{~km}$ total).

The error bars indicate that the fuel consumption for a conventionally weighted container on a truck is expected to fall between $1.89 \mathrm{~L} / 100 \mathrm{~km}$ and $2.35 \mathrm{~L} / 100 \mathrm{~km} 95 \%$ of the time, while the most lightweight container (aluminum scenario) results in a fuel consumption between 1.48 $\mathrm{L} / 100 \mathrm{~km}$ and $1.85 \mathrm{~L} / 100 \mathrm{~km}$. The train FC for a conventional container is expected to range between $0.37-0.91 \mathrm{~L} / 100 \mathrm{~km} 95 \%$ of the time, while the most lightweighted container (aluminum scenario) will have a fuel consumption on a train ranging from $0.29 \mathrm{~L} / 100 \mathrm{~km}$ to $0.71 \mathrm{~L} / 100 \mathrm{~km}$. The conventional container on a ship will have a fuel consumption ranging from $0.49 \mathrm{~L} / 100 \mathrm{~km}$ to $0.85 \mathrm{~L} / 100 \mathrm{~km} 95 \%$ of the time, and the aluminum lightweighting scenario will result in a range of fuel consumption from $0.38 \mathrm{~L} / 100 \mathrm{~km}$ to $0.67 \mathrm{~L} / 100 \mathrm{~km}$. Monte Carlo simulations were conducted so that each input was randomly varied for only one set of trials $(n=10,000)$, meaning that the same set of randomized inputs were used to produce the range of values for each lightweighting scenario. Thus, the high end of the fuel consumption error bar for a conventionally weighted container should be compared to the high end of the error bar for a lightweighted container to understand the effects of the different lightweighting options. It is clear, therefore, that despite the uncertainty in FRV and resulting FC, the reduction in FC will stay constant. For instance, whichever percentile result chosen within the $95 \%$ interval, the aluminum lightweighting scenario will result in $21 \%$ reduction in truck fuel consumption. Refer to Appendix A for more detail regarding the Monte Carlo sensitivity analysis.

Lightweighting the container, regardless of scenario, had a strong impact on fuel savings over the container's lifetime, as even the most modest lightweighting scenario (reducing panel and 
roof mass by $10 \%$ ) lead to a reduction of 1,290 $\mathrm{L}$ of diesel and 1,330 $\mathrm{L}$ of residual fuel oil over the container's lifetime. Replacing the container's wall panels and roof with aluminum reduced diesel use by approximately $5,800 \mathrm{~L}$ and residual fuel oil by $6,000 \mathrm{~L}$, which amounted to $\$ 5,600$ assuming a diesel fuel price of $\$ 0.63 / \mathrm{L}$ and a residual fuel oil price of $\$ 0.32 / \mathrm{L}$ (U.S. Energy Information Administration, 2017b, 2017c).

Fuel intensity is a commonly used metric in transportation, and Figure 2 illustrates the changes in fuel intensity for each mode and each lightweighting scenario, assuming constant cargo. It was assumed that the loaded cargo mass per container was 7 metric tons.

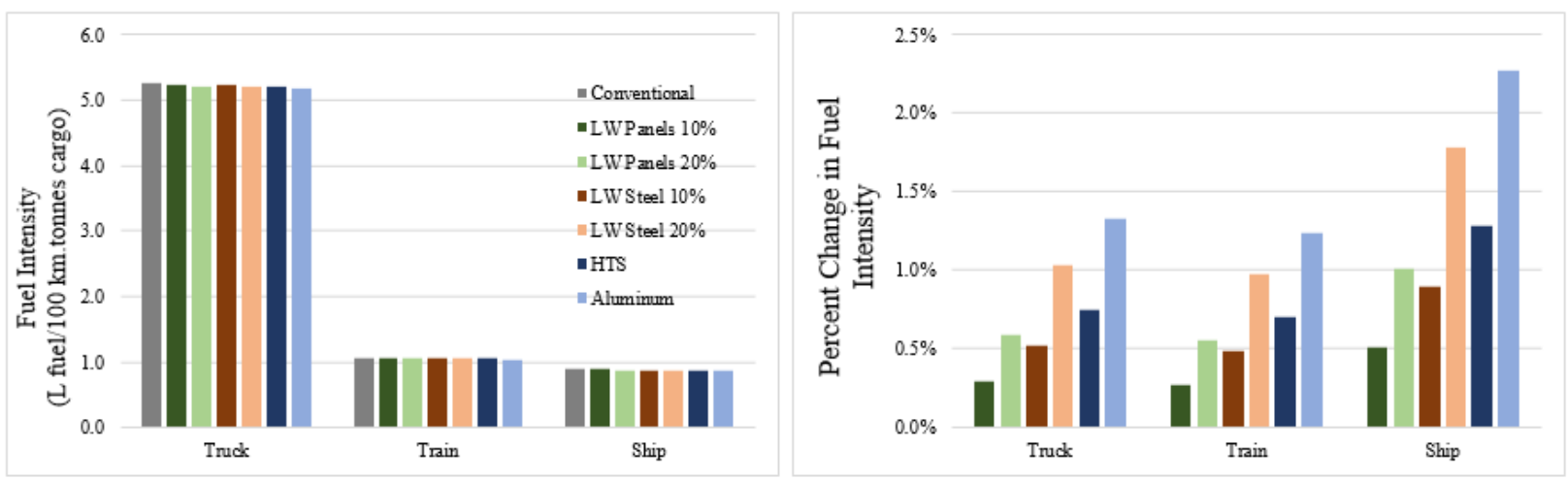

Figure 2 Fuel Intensity Trends. Fuel intensities and the respective percent savings at constant payload for the transportation of lightweighted containers compared to a conventional container.

Figure 2 indicates that the largest percent change in fuel intensity for each mode occurred with the aluminum replacement scenario, and that the largest reduction in modal fuel intensity occurred for the ship. Given that the absolute $F_{\text {int }}$ value for the ship mode was the lowest, it showing the highest $\% \Delta \mathrm{F}_{\text {int }}$ was unexpected. Further, a comparison of fuel/mass elasticity values $(\% \Delta \mathrm{FC} / \% \Delta \mathrm{M})$ among the three modes ( 0.38 for truck, 0.33 for rail, and 0.84 for ship) shows that the value for the ship was also the highest, again unexpectedly. While these results were not anticipated, we expect that the reason for the large ship fuel savings was due to the 
lack of a complete expression for the mass dependence of ship FC. This lead to the use of an approximate FRV (determined from modeled fuel vs. mass relationships (ABS, 2013) where ship block coefficients were adjusted to maintain constant dead-weight) that most likely overstated the importance of mass on a ship's fuel consumption.

\subsubsection{Operation - constant overall mass}

Assuming constant overall mass, the overall environmental burdens and fuel consumption were the same for the lightweighted container as for the conventional container, since the total loaded vehicle mass remained unchanged. However, the fuel intensity still decreased, because the same fuel was allocated over more tonnes of cargo. As more mass was removed from the container through lightweighting, the difference in intensity between assuming constant cargo and constant overall mass became more pronounced. When replacing nonstructural steel with aluminum, fuel intensity assuming constant overall mass was reduced by approximately $9 \%$ from the constant cargo assumption. Adding cargo mass equal to the reduction in mass achieved through lightweighting clearly improved energy and fuel intensity beyond improvements resulting from container lightweighting alone.

\subsubsection{End-of-Life}

End-of-life burdens associated with transportation, dismantling, and shredding were computed using the recycled content approach. Burdens for all of these processes were a direct function of the mass of material processed. Since steel is highly recyclable, all results assumed a recycling rate of $90 \%$. End-of-life processes for a conventional container required 3.8 GJ of energy and released 0.3 tonnes $\mathrm{CO}_{2} \mathrm{e}$ of GHG. Similar to the use stage, the two most effective 
lightweighting scenarios were $20 \%$ mass reduction of all steel (resulting in a $20 \%$ reduction in environmental burdens) and aluminum replacement (a 24\% reduction in burdens).

\subsubsection{Life Cycle}

Figure 3 illustrates the life cycle energy demand incurred by an individual container over its lifetime, by life cycle stage. Production in the figure includes material production and container manufacturing processes. These results assumed the Constant Cargo scenario. The error bars around the total energy demand values once again illustrate the $95 \%$ prediction interval as determined by a set of Monte Carlo simulations, meaning that we will expect to see life cycle energy demand fall within the indicated range $95 \%$ of the time. Uncertainty in these results arise due to uncertainty in the modal FRVs as well as in the lifetime distances traveled by a container on a truck, train, and ship. Further information regarding the uncertainty analysis can be found in Appendix A.

The use stage dominated life cycle energy demand, accounting for approximately $95 \%$ of the total energy. End-of-life burdens related to transportation, dismantling, and shredding were extremely small by comparison. Replacing the container's walls and roof with aluminum reduced energy and emissions the most, more than compensating for an increased production burden. This scenario achieved energy savings of approximately $450 \mathrm{GJ}$ and a reduction in emissions of 39 tonnes of $\mathrm{CO}_{2} \mathrm{e}$ over the container's 15 -year lifetime, a $17 \%$ reduction. Lightweighting a container's steel by $20 \%$ was the next best option, saving 434 GJ of energy and 35 tonnes $\mathrm{CO}_{2}$ e of GHG. To put these results in context, a typical passenger car emits 61.3 tonnes $\mathrm{CO}_{2} \mathrm{e}$ of $\mathrm{GHG}$ emissions and requires $995 \mathrm{GJ}$ of energy over its lifetime (Center for Sustainable Systems, University of Michigan, 2016). 


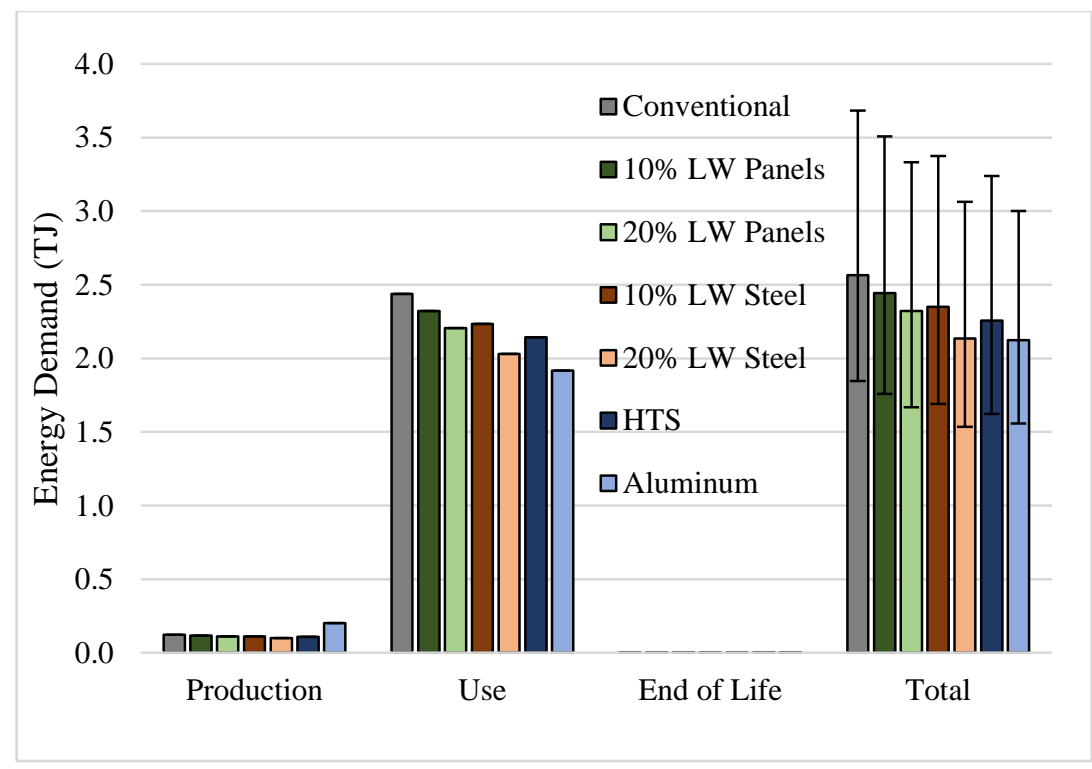

Figure 3 Single Container Life Cycle Energy Demand. Life cycle energy required for one shipping container over its lifetime, assuming constant cargo scenario. The error bars indicate the range within which life cycle energy demand is expected to fall $95 \%$ of the time, based on uncertainty in FRV. The same sets of randomized values for FRV and lifetime distances were used for each $L W$ scenario. Therefore, different lightweighting scenarios should be compared at the same percentile.

Uncertainty analysis indicates that the life cycle energy demand for a conventional container is expected to range from $1.9 \mathrm{TJ}$ to $3.7 \mathrm{TJ} 95 \%$ of the time, and the most lightweighted container (aluminum scenario) will result in a life cycle energy demand between 1.6 TJ and 3.0 TJ. While the absolute values of the results will differ due to the uncertainty in modal FRV and lifetime distance, the relative reduction in burdens between the conventional and lightweighting scenarios remains the same, whichever percentile selected within the $95 \%$ interval. For instance, the aluminum lightweighting scenario saves $17 \%$ of the conventional life cycle energy demand, based on the mean of the Monte Carlo results, which is the same reduction observed in our deterministic model. The uncertainty in life cycle GHG emissions follows the same trend as uncertainty in life cycle energy, with values ranging from 148 tonnes 
$\mathrm{CO}_{2} \mathrm{e}$ to 300 tonnes $\mathrm{CO}_{2} \mathrm{e}$ of GHG for a conventional container. Refer to Appendix A for complete Monte Carlo sensitivity analysis results.

\subsection{National and Global Level Burdens and Savings}

\subsubsection{National Savings (Truck and Train)}

We calculated the U.S. fleet to be approximately 1.2 million forty-foot containers. Given this fleet size, the energy and GHG emission burdens and potential savings from lightweighting were estimated at the national scale. The Jones Act restricts domestic shipping in the United States to vessels owned by, operated by, and employing U.S. citizens (Kashian et al., 2017; Legal Information Institute, 2009; Valentine, 2017). That, in addition to physical constraints of domestic channels, mainly the Mississippi river (Morris, 2015), means that the only significant domestic ship freight transport is conducted on barges (M Collette 2017, personal communication, 30 May, Naval Architecture and Marine Engineering, University of Michigan). It was assumed that containers are moving only by truck and train within the United States, with a modal split of $66 \%$ truck and $34 \%$ train based on distance traveled (total lifetime distance: 1,642,000 km). Figure 4 illustrates the life cycle energy demand of the U.S. container fleet. The error bars for total energy demand represent the $95 \%$ expected range in life cycle energy demand resulting from a set of Monte Carlo simulations (from the $2.5^{\text {th }}$ to $97.5^{\text {th }}$ percentile). Please refer to Appendix A for complete information regarding the uncertainty analysis.

The U.S. conventional container fleet's lifetime operational fuel use was determined to be 32 billion liters of diesel fuel, and its life cycle burdens were 1.54 EJ of energy and 121 million tonnes of $\mathrm{CO}_{2} \mathrm{e}$ using our assumed values for FRV, lifetime distances, and number of 


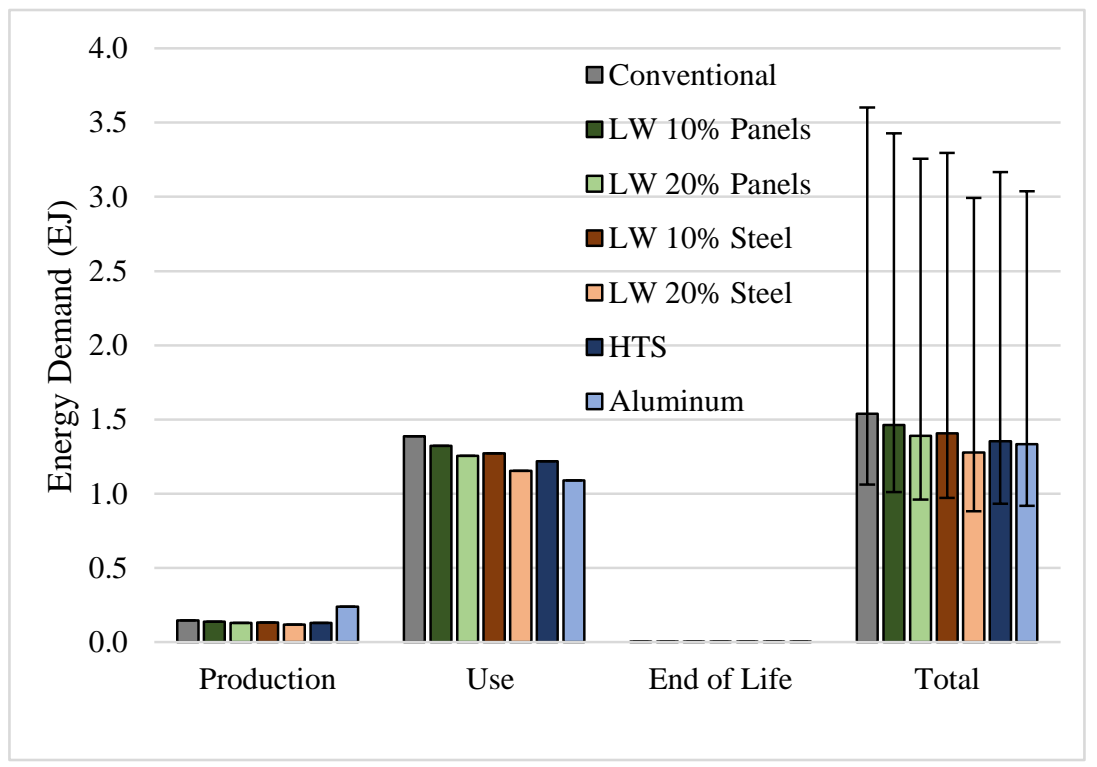

Figure 4 U.S. Container Fleet Life Cycle Energy Demand. Life cycle energy demand of U.S. shipping container fleet, constant cargo scenario. The error bars indicate the range within which life cycle energy demand is expected to fall $95 \%$ of the time, based on uncertainty in FRV. The same sets of randomized values for FRV and lifetime distances were used for each $L W$ scenario. Therefore, different lightweighting scenarios should be compared at the same percentile.

containers. Life cycle savings from lightweighting all steel by $20 \%$ were $0.26 \mathrm{EJ}, 21$ million tons of $\mathrm{CO}_{2} \mathrm{e}$, and 5.4 billion liters of diesel fuel. By replacing the U.S. container fleet's roof and wall panels with aluminum, savings were $0.20 \mathrm{EJ}, 19.4$ million tonnes of $\mathrm{CO}_{2} \mathrm{e}$, and 6.9 billion liters of diesel fuel, which amounted to approximately $\$ 4.4$ billion in fuel savings at \$0.63/L diesel fuel (U.S. Energy Information Administration, 2017c). For comparison, annual U.S. energy consumption is approximately $100 \mathrm{EJ}$, of which truck, train, and ship freight transportation account for 6.3 EJ (Davis et al., 2016; Energy Information Administration, 2017). As in the previous results, uncertainty in inputs such as modal FRV, lifetime distances, and fleet size will drive relatively significant changes in the results. It is clear that total life cycle energy demand for the U.S. shipping container fleet can range from $1.06 \mathrm{EJ}$ to $3.6 \mathrm{EJ}$ if all containers were conventional, and that this life cycle energy can be reduced to between 0.88 EJ - 2.99 EJ if all containers' steel were lightweighted by $20 \%$. Despite this uncertainty, the 
savings remain consistent for each lightweighting scenario. For example, the $20 \%$ steel lightweighting scenario results in a $17 \%$ reduction in burdens, no matter where in the $95 \%$ prediction interval the conventional container value falls. Life cycle GHG emissions for the U.S. container fleet follow a similar trend, with a conventional container fleet's life cycle GHG emissions ranging between 84 and 283 million tonnes $\mathrm{CO}_{2} \mathrm{e}$, with a $17 \%$ reduction in burdens for the $20 \%$ steel lightweighting scenario. A complete analysis of the uncertainty is included in Appendix A. Despite the range in results caused by the uncertainty in inputs, it is clear that lightweighting containers has the potential to reduce transportation energy and GHG emissions significantly while also having a positive economic impact, based on fuel savings calculations above.

Comparing Figures 3 and 4, it is apparent that the trends differ: for the single container life cycle, the best lightweighting scenario was aluminum replacement, whereas for the national scale life cycle, the best lightweighting scenario was $20 \%$ reduction in all steel. This difference occurred because the container fleet within the United States was assumed to be transported only by truck and train (1.6 million $\mathrm{km}$ total distance), whereas the single container life cycle assumed that the ship accounted for over $70 \%$ of total lifetime distance (6 million $\mathrm{km}$ total). The larger total distance caused the use stage for the single container life cycle to be significantly larger, relative to the use stage of the U.S. container fleet. This caused the U.S. fleet production stage to have a greater impact relative to total life cycle burdens than for a single container life cycle. As the aluminum replacement scenario was the most intensive in the production stage, the overall life cycle burden for the aluminum replacement scenario was greater than the $20 \%$ steel lightweighting scenario for the U.S. fleet. 


\subsubsection{Global Savings (Ship)}

Life cycle results for the global fleet indicate the impact lightweighting shipping containers could have on energy consumption and GHG emissions. The global fleet of shipping containers is approximately 17.5 million forty-foot containers (World Shipping Council, 2017b), and was assumed to be transported only by ship for this analysis. Figure 5 shows life cycle energy demand of the global fleet, assuming 3,580,000 km of travel per container over a lifetime of 15 years. GHG emissions followed a similar trend. The error bars on the total energy demand values illustrate the empirical 95\% prediction interval from a Monte Carlo sensitivity analysis, based on uncertainty in ship FRV, lifetime distance, and global fleet size. A complete description of the uncertainty analysis is included in Appendix A.

The use stage again dominated life cycle energy and GHG emissions. Figure 5 shows that savings from lightweighting all of the containers' steel by $20 \%$ was 3.6 EJ, a $17 \%$ reduction in burdens assuming our deterministic input values. Replacing wall panels and roof with aluminum would result in energy savings of $2.7 \mathrm{EJ}$, or $13 \%$. Fuel savings would be $\$ 28$ billion, assuming the aluminum replacement scenario and a residual fuel oil price of $\$ 0.32 / \mathrm{L}$ (U.S. Energy Information Administration, 2017b). The Monte Carlo sensitivity analysis indicates that $95 \%$ of the time we expect the global shipping container fleet to have a life cycle energy demand between 7.8 EJ and 51.4 EJ and life cycle emissions between 0.52 and 4.0 billion tonnes $\mathrm{CO}_{2} \mathrm{e}$ of GHG if all containers are conventional. In a $20 \%$ steel lightweighting scenario, the life cycle energy demand is expected to drop to between $7.3 \mathrm{EJ}$ and $43.5 \mathrm{EJ}$ and life cycle emissions will range between 0.41 and 3.1 billion tonnes $\mathrm{CO}_{2} \mathrm{e}$ of $\mathrm{GHG}$ (savings of $17 \%$ for both life cycle energy and emissions). While the absolute total life cycle energy and emissions 


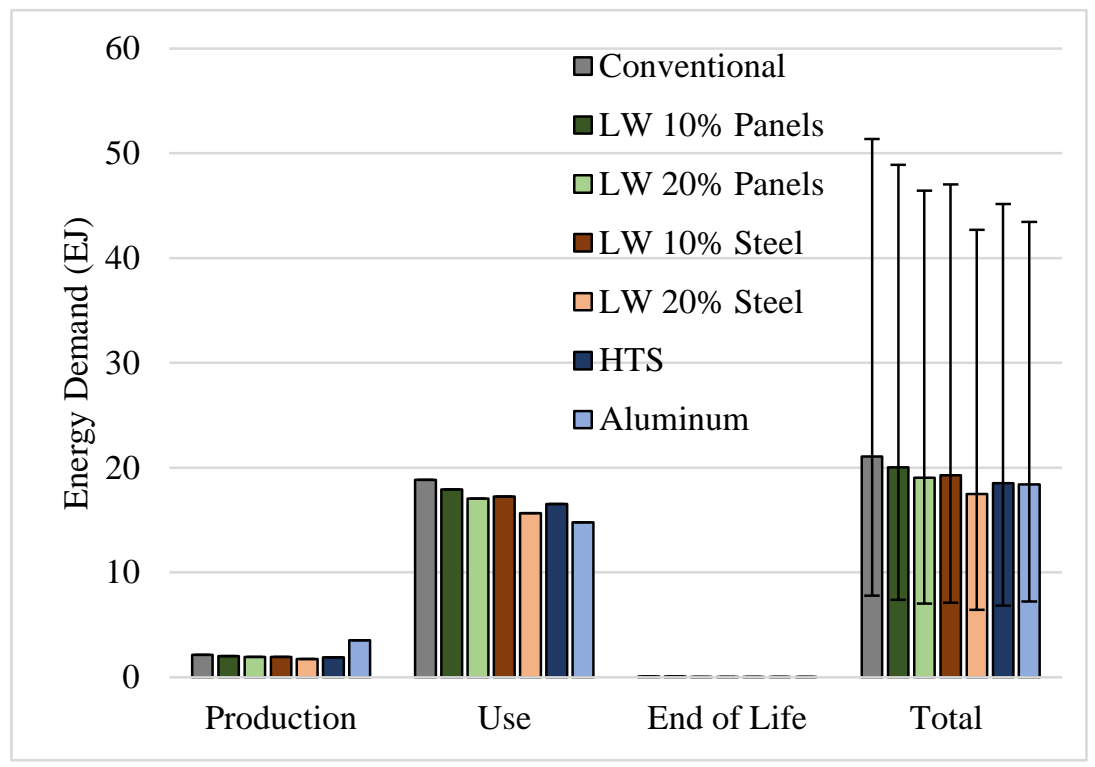

Figure 5 Global Container Fleet Life Cycle Energy Demand. Life cycle energy demand for global fleet of shipping containers, constant cargo scenario. The error bars indicate the range within which life cycle energy demand is expected to fall $95 \%$ of the time, based on uncertainty in FRV. The same sets of randomized values for FRV and lifetime distances were used for each $L W$ scenario. Therefore, different lightweighting scenarios should be compared at the same percentile.

vary due to the uncertainty in input parameters, the reduction due to lightweighting will follow the same trends reported by our deterministic model.

Comparing Figure 5 to Figures 3 and 4, it is apparent that trends once again differ. Similar to the national scale life cycle energy demand presented in Figure 4, reducing the global fleet's steel mass by $20 \%$ resulted in the greatest reduction in burdens, as opposed to the single container life cycle (Figure 3), where aluminum replacement was best. This was due to the decreased total lifetime distance (3.6 million $\mathrm{km}$ ) relative to a single container's lifetime distance (6 million $\mathrm{km})$, which made the production burden more influential for the global scale, causing the aluminum replacement scenario (with its higher production burdens) to be less desirable. This decreased distance relative to a single container's lifetime distance is due in part to the lack of truck and train modes in the global modeling approach (in which only ships were considered), as well as to the fact that the average shipping distance over many 
different routes was lower than the average shipping distance for the U.S. centric shipping routes. While the best lightweighting scenario was the same for the U.S. and global scale life cycle energy demand, the relative contribution of the production burden differed between the two. This was due to the effects of modal distribution and total distance traveled. The production burden had a greater effect on global scale life cycle energy (accounting for 10\%) than national scale life cycle energy (accounting for 9\%) because the global use burden was comprised entirely of burdens from ship transportation, which was more efficient than the truck mode that drove the national scale use burden. This increased efficiency sufficiently overcame the burden associated with the increased lifetime distance assumed for the global scale calculations over the national scale.

\subsection{Case Studies (Multimodal)}

\subsubsection{Shanghai to Detroit}

This case study demonstrated a typical multimodal shipping container haul via ship, train, and truck modes, and compared results when shipping via the west coast versus via the Panama Canal and east coast. This case assumed 7 metric tonnes of cargo in the shipping container, however, as mentioned in the methods section, the model assumes a cargo mass per container of 20.6 tonnes on the ship because of the expected addition of ballast. The routing through the west coast case was from Shanghai, China to Los Angeles, CA 10,960 km by ship, 3,400 km to Chicago, IL by rail, and $430 \mathrm{~km}$ to Detroit, MI by truck. Residual fuel oil consumption was 680 liters, and diesel consumption was 410 liters. Total energy demand for this trip, including allocated production and end-of-life burdens, for the conventional container was approximately 49,200 MJ, with a corresponding 4.0 tonnes $\mathrm{CO}_{2} \mathrm{e}$ of $\mathrm{GHG}$ emissions. The Monte Carlo uncertainty analysis indicated that the interquartile range of the conventional 
energy demand is from 51,500 MJ to 55,400 MJ, based on uncertainty in modal FRV, modal distances traveled, cargo load, and vehicle fuel consumption. Refer to Appendix A for more details on the Monte Carlo analysis. Lightweighting the container's steel by $20 \%$ resulted in reductions of 12 liters of residual fuel oil and 4 liters of diesel fuel for this trip. Total energy savings including production and end-of-life burdens would be $790 \mathrm{MJ}$ and there would be a reduction in GHG emissions of approximately $65 \mathrm{~kg} \mathrm{CO}_{2} \mathrm{e}$ per container. By replacing the Corten A wall panels and roof with aluminum, fuel use decreased by 15.5 liters of residual fuel oil and 5 liters of diesel fuel per container. Total energy savings including production and endof-life burdens were $733 \mathrm{MJ}$ with a corresponding reduction in $\mathrm{GHG}$ emissions of $69 \mathrm{~kg} \mathrm{CO}_{2} \mathrm{e}$. While the uncertainty in inputs affects the absolute value of the savings, the percentage reduction stays consistent no matter where one falls in the $95 \%$ prediction interval. A container ship carrying 2,250 containers along the West route would use \$1.1 million dollars in fuel at a diesel fuel cost of $\$ 0.63 / \mathrm{L}$ and residual fuel oil price of $\$ 0.32 / \mathrm{L}$ (U.S. Energy Information Administration, 2017c, 2017b). Lightweighting containers through material substitution with aluminum saved $\$ 18,615$ in fuel for this trip. As described in the Methods section, total travel time was determined to be approximately 16 days and 6 hours, neglecting any train or truck delays.

Distances for routing through the east coast via the Panama Canal were 19,600 km by ship from Shanghai to Newark, and $993 \mathrm{~km}$ by train from Newark to Detroit. Residual fuel oil consumption was 1,220 liters and diesel fuel consumption was 74 liters. Total energy demand for the conventional container's trip was 59,000 MJ. GHG emissions were approximately 5 tonnes $\mathrm{CO}_{2} \mathrm{e}$ of $\mathrm{GHG}$ emissions. The interquartile range of the Monte Carlo results for energy demand for this case study is bounded by $62,800 \mathrm{MJ}$ and $68,000 \mathrm{MJ}$, based on uncertainty in 
modal FRV, modal distances traveled, cargo load, and vehicle fuel consumption. Refer to Appendix A for more details on the Monte Carlo findings. Lightweighting all of the container's steel by $20 \%$ saved 22 liters of residual fuel oil and 0.7 liters of diesel fuel. Total energy savings, after considering production and end-of-life burdens, were 1,100 MJ, with an associated reduction in GHG emissions of $92 \mathrm{~kg} \mathrm{CO}_{2} \mathrm{e}$ for this lightweighting scenario. Replacing the wall panels and roof with aluminum would save 28 liters of residual fuel oil and 0.9 liter of diesel fuel per container. Total energy savings (including production and end-oflife burdens) were 1,020 MJ of energy and the reduction in $\mathrm{GHG}$ emissions was $98 \mathrm{~kg} \mathrm{CO}_{2} \mathrm{e}$ per container. While uncertainty in the inputs affects the absolute value of the savings, the percentage reduction stays consistent no matter where one falls in the $95 \%$ prediction interval. For a container ship with 2,250 forty-foot containers, fuel costs were around $\$ 967,000$, and total fuel savings for transporting lightweighted containers from Shanghai to Detroit would be $\$ 21,100$ assuming the aluminum replacement scenario and the same fuel costs as above. Total travel time, neglecting any delays, was 23 days and 15 hours.

Comparing the east and west coast routes, shipping through the Panama Canal to the east coast required more energy and more time than shipping via the west coast. While energy and time followed the same trend, cost was lower via the east coast due to the increased distance via the (least expensive) ship mode. Similar to the national and global scale life cycle energy demands, the overall energy burden of aluminum was higher than the $20 \%$ LW steel scenario for both the east and west coast routes, due to the influence of aluminum's increased material production burden. As discussed previously, the altered modal distribution for this case as compared to a single container's life cycle (proportion of ship distance rises from $70 \%$ to $96 \%$ ) affected the operational stage burden since the ship was a more efficient mode. This made the 
material production burden relatively more significant for the case study than for the single container over its lifetime. This added influence made the aluminum replacement scenario more energy intensive overall despite higher fuel savings in the operational stage. Along with demonstrating the effect of lightweighting, this case study highlighted the influence of route selection on fuel consumption, energy demand, and GHG emissions. Even the most effective lightweighting scenario for transportation through the east coast required $16 \%$ more energy than the conventional transportation scenario through the west coast. Clearly, along with lightweighting containers, choosing efficient routes is important to reducing environmental burdens of transporting freight on containers.

\subsubsection{Rotterdam to Pittsburgh}

This case demonstrated the impacts of multimodal shipping from Europe to North America, which is the second largest shipping route for the United States (UNCTAD, 2015). It was assumed that a loaded container ( 7 metric tons cargo, but 20.6 metric tons modeled on a ship due to additional ballast) traveled from Rotterdam in the Netherlands to New York-Newark 6,200 km by ship, then $580 \mathrm{~km}$ by truck to Pittsburgh, Pennsylvania. Residual fuel oil consumption was 385 liters and diesel fuel consumption was 213 liters per container. Total energy demand for the conventional container's trip was 27,000 MJ, and GHG emissions amounted to approximately 2.2 tonnes $\mathrm{CO}_{2} \mathrm{e}$. The interquartile range of the Monte Carlo distribution from the uncertainty analysis for this case was from 28,300 MJ to 30,400 MJ. By lightweighting all of the container's steel by $20 \%, 7$ liters of residual fuel oil and 2.2 liters of diesel fuel would be saved. Full life cycle energy savings were approximately $435 \mathrm{MJ}$, which corresponded to a reduction in GHG emissions of $36 \mathrm{~kg} \mathrm{CO}_{2} \mathrm{e}$. By replacing the container's wall panels and roof with aluminum, 9 liters of residual fuel oil and 3 liters of diesel fuel would 
be saved. After taking into account production and end-of-life burdens and savings, total energy savings would amount to $430 \mathrm{MJ}$ of energy with a resulting reduction of GHG emissions of $39 \mathrm{~kg} \mathrm{CO}$ e. Percentage reduction in burdens stayed consistent despite the uncertainty in vehicle fuel consumption, modal FRV, modal distance, and cargo load. Fuel costs associated with this trip are around $\$ 580,000$, and savings would be $\$ 10,300$ for a container ship filled with 2,250 forty-foot lightweight containers, assuming the same fuel prices as above and the aluminum lightweighting scenario. Total travel time was determined to be 8 days and 10 hours, neglecting delays on the road.

Backhauling, or empty repositioning of a container to its point of origin, is a relatively frequent occurrence that should be modeled in order to fully evaluate impacts of the freight transportation system. Due to a trade imbalance between the Far East and North America, a large percentage of containers are often shipped empty (Theofanis and Boile, 2009). Along with modeling the European-North American route, this case was also used to model the effect of backhauling. It was assumed that an empty container was transported by truck from Pittsburgh to the closest port (Baltimore, MD) before being shipped back to Rotterdam. The distance by truck was $400 \mathrm{~km}$, and the shipping distance to Rotterdam from Baltimore was $6,600 \mathrm{~km}$. This would require an additional 130 liters of diesel fuel and 412 liters of residual fuel oil. The total environmental burdens for a conventional container's trip would be 51,400 $\mathrm{MJ}$ of energy and 4.2 tonnes $\mathrm{CO}_{2} \mathrm{e}$ of GHG emissions, with the uncertainty analysis indicating an interquartile range between 55,000 MJ and 58,800 MJ. For this case, backhauling accounted for approximately $47 \%$ of total burdens and costs.

By lighweighting the container's steel by $20 \%$, savings for the total trip, including backhauling, were 14 liters of residual fuel oil and 3.7 liters of diesel fuel. After taking into account 
production and end-of-life burdens and savings, total energy savings would be $863 \mathrm{MJ}$ of energy, with a resulting reduction in $\mathrm{GHG}$ emissions of $72 \mathrm{~kg} \mathrm{CO} 2$. By replacing the wall panels and roof with aluminum, 18.2 liters of residual oil and 4.8 liters of diesel are saved which, after considering production and end-of-life burdens and savings, would amount to 845 MJ of energy and $78 \mathrm{~kg} \mathrm{CO}_{2} \mathrm{e}$ of $\mathrm{GHG}$ emissions. Percentage reduction in burdens stays consistent no matter the uncertainty in input parameters. Fuel costs for this total trip, including backhauling, were approximately $\$ 1.1$ million, and total savings were $\$ 19,820$ assuming a container ship carrying 2,250 forty-foot containers, all of the containers' roofs and panels were made of aluminum, and the same fuel costs as above. Once again, the aluminum replacement scenario resulted in lower energy and emissions savings than the $20 \%$ reduction in steel mass despite higher fuel savings due to altered modal distribution that made the increased aluminum production burden more influential. Total trip time would be 16 days and 6 hours, assuming there are no delays.

As intuition suggests, this case demonstrated that backhauling increased energy demand and total trip time, almost doubling both, because the longest part of the journey, between the East Coast of the United States and Rotterdam was being repeated, albeit with no cargo. Backhauling also resulted in increased cost for the same reasons.

\section{Conclusion}

Life cycle energy and GHG emission effects from lightweighting shipping containers were investigated across modes and geographic scales. Fuel consumption was also determined for the operational stage. The study indicated that the operational stage was responsible for $95 \%$ 
of a single container's life cycle energy and emissions impacts. Depending on modal distribution and distances traveled, either replacing non-structural steel components with aluminum or lightweighting all steel by $20 \%$ resulted in the most significant reduction in impacts across the six lightweighting scenarios studied. The results for one container were scaled up to reflect the total number of containers both in the United States and globally, demonstrating the significant potential fuel and energy savings possible through lightweighting shipping containers. Replacing the global fleet of containers' roof and wall panels with aluminum would result in fuel savings equivalent to $\$ 28$ billion, and reducing steel mass by $20 \%$ would result in $17 \%$ reduction in container life cycle energy and emissions, equivalent to 3.6 EJ of energy demand. As a comparison, annual U.S. energy consumption is about $100 \mathrm{EJ}$, of which truck, train, and ship freight transportation account for 6.3 EJ (Davis et al., 2016; Energy Information Administration, 2017). Two case studies were presented to demonstrate the savings achievable through lightweighting on typical intercontinental freight hauls and to compare the effects of different ports and routes, as well as the inclusion of backhauling. Based on the case studies, energy increased with trip time, but fuel cost was influenced by differences in fuel prices for each of the modes, and so cost did not necessarily increase with journey time. A Monte Carlo sensitivity analysis was conducted to demonstrate that despite uncertainty in several input parameters, the expected savings through lightweighting remain constant.

The results noted here have important policy implications. Since truck is the most fuel intensive mode, the greatest reduction in energy demand and GHG emissions occurred when containers that were being moved on trucks are lightweighted. This is important when considering whether lightweighting efforts should be focused on intercontinental travel, where ships dominate burdens, or domestic travel, where trucks dominate burdens. Due to the intermodal 
nature of freight transportation and container use, it may not be possible to isolate one mode for lightweighting, but when possible, this study demonstrates that these efforts should primarily be applied to domestic containers that are more likely to be carried on the least fuel efficient mode. In addition to showing the positive impact of lightweighting, the case studies demonstrated the influence of route selection on environmental burdens. For container freight transportation burdens to be minimized, the most efficient route needs to be adopted in addition to selecting the best container lightweighting scenario.

Future work should confirm that lightweighting process innovations are feasible and do not compromise the structural integrity, function, or lifetime of the shipping container. While the relationship between ship mass and fuel consumption is expected to be nonlinear, it was assumed that an incremental change in mass would allow one to calculate the resulting fuel consumption using FRVs that were based on a fully loaded ship (cargo and ballast). This relationship could be more accurately represented for different size ships and cargo loadings. Additionally, only average speeds were used to estimate traveling distances for each of the modes. Future studies could consider the effects of lightweighting on a more comprehensive speed profile that incorporates maneuvering at sea and in port, in addition to average cruising speeds. Moreover, the environmental benefits of lightweighting considered in this study were fuel savings, and the reduction in energy consumption and GHG emissions. Future work should consider the impact of lightweighting on other emissions, such as $\mathrm{SO}_{\mathrm{x}}, \mathrm{NO}_{\mathrm{x}}$, and $\mathrm{PM}$, which are known to be produced through shipping and have significant environmental consequences (Corbett et al., 1999). Lastly, it is necessary to determine which components of a container can be lightweighted. It was observed that lightweighting all of the steel in the container could 
achieve the greatest reduction in burdens depending on distance traveled and modes used, though it is unknown whether all of these components can be lightweighted without compromising the container. Nonetheless, the findings of this study indicated that lightweighting containers could be an effective method to reduce transportation energy and environmental burdens associated with freight transport. The magnitude of the lightweighting effects across modes and national and global scales highlighted in this study demonstrates the opportunities for significant fossil fuel savings and climate change mitigation. 


\section{References}

ABS, 2013. Ship Energy Efficiency Measures.

Alphaliner, 2016. Monthly monitor, September 2016.

American Association of State Highway and Transportation Officials, 2002. Transportation: Invest in America, Freight-Rail Bottom Line Report. Am. Assoc. State Highw. Transp. Off.

American Trucking Associations, 2017. Reports, Trends \& Statistics [WWW Document]. URL http://www.trucking.org/News_and_Information_Reports_Industry_Data.aspx (accessed 6.26.17).

Ang-Olson, J., Schroeer, W., 2002. Energy efficiency strategies for freight trucking potential impact on fuel use and greenhouse gas emissions. Transp. Res. Rec. 11-18.

Argonne National Laboratory, 2017. GREET Model [WWW Document]. URL https://greet.es.anl.gov (accessed 5.18.17).

Argonne National Laboratory, 2016a. The Greenhouse Gases, Regulated Emissions, and Energy Use in Transportation (GREET) Model Software: GREET 1, Version 2011 Copyright (C) 1999 UChicago Argonne, LLC.

Argonne National Laboratory, 2016b. The Greenhouse Gases, Regulated Emissions, and Energy Use in Transportation (GREET) Model Software: GREET 2, Version 2.7 Copyright (C) 2007 UChicago Argonne, LLC.

Athena Sustainable Materials Institute, 2012. A Cradle-to-Gate Life Cycle Assessment of Canadian Glulam Manufacture : An Update 38.

Bachmann, C., Chingcuanco, F., MacLean, H., Roorda J, M., 2015. Life-Cycle Assessment of Diesel-Electric Hybrid and Conventional Diesel Trucks for Deliveries. J. Transp. Eng. 141, Content ID 05014008. doi:10.1061/(ASCE)TE.1943-5436.0000761.

Budget Shipping Containers, 2016. How many Shipping Containers are there in the World? [WWW Document]. URL http://www.budgetshippingcontainers.co.uk/info/how-manyshipping-containers-are-there-in-the-world/ (accessed 2.19.18).

Bureau of International Recycling, 2017. Stainless Steel \&amp; Special Alloys [WWW Document]. URL http://www.bir.org/industry/stainless-steel/ (accessed 7.13.17).

Burnson, P., 2012. Logistics Management.

Castonguay, J., 2009. International Shipping: Globalization In Crisis. Witness 2-4.

Center for Sustainable Systems University of Michigan, 2016. Personal Transportation Factsheet.

Chester, M., Horvath, A., 2010. Life-cycle assessment of high-speed rail: the case of California. Environ. Res. Lett. 5, 014003. doi:10.1088/1748-9326/5/1/014003

Corbett, J.J., Fischbeck, P.S., Pandis, S.N., 1999. Global nitrogen and sulfur inventories for oceangoing ships. J. Geophys. Res. 104, 3457-3470. doi:10.1029/1998JD100040

Davis, S.C., Williams, S.E., Boundy, R.G., 2016. Transportation Energy Data Book Edition 35.

Delorme, A., Karbowski, D., Vijayagopal, R., Sharer, P., 2009. Evaluation of Fuel Consumption Potential of Medium and Heavy Duty Vehicles through Modeling and Simulation, Report to NAS - Contract DEPS-BEES-001. Argonne National Laboratory.

Descalle, M.A., Manatt, D., Slaughter, D., 2006. Analysis of Recent Manifests for Goods Imported through US Ports.

DSV, n.d. Dry Containers [WWW Document]. URL http://www.dsv.com/sea-freight/seacontainer-description/dry-container (accessed 5.18.17). 
Energy Information Administration, 2017. Monthly Energy Review [WWW Document]. URL https://www.eia.gov/totalenergy/data/monthly/ (accessed 5.18.17).

Facanha, C., Horvath, A., 2007. Evaluation of life-cycle air emission factors of freight transportation. Environ. Sci. Technol. 41, 7138-7144. doi:10.1021/es070989q

Finkbeiner, M., Rethmeier, M., Chang, Y.-J., Pittner, A., Sproesser, G., 2015. Enviromental Impacts of Welding Methods. Laser Mag. from TRUMPF 6.

Finnveden, G., Hauschild, M.Z., Ekvall, T., Guinée, J., Heijungs, R., Hellweg, S., Koehler, A., Pennington, D., Suh, S., 2009. Recent developments in Life Cycle Assessment. J. Environ. Manage. 91, 1-21. doi:10.1016/j.jenvman.2009.06.018

Frischknecht, R., 2010. LCI modelling approaches applied on recycling of materials in view of environmental sustainability, risk perception and eco-efficiency. Int. J. Life Cycle Assess. 15, 666-671. doi:10.1007/s11367-010-0201-6

Galos, J., Sutcliffe, M., Cebon, D., Piecyk, M., Greening, P., 2015. Reducing the energy consumption of heavy goods vehicles through the application of lightweight trailers: Fleet case studies. Transp. Res. Part D Transp. Environ. 41, 40-49. doi:10.1016/j.trd.2015.09.010

Hellweg, S., Milà i Canals, L., 2014. Emerging approaches, challenges and opportunities in life cycle assessment. Science 344, 1109-13. doi:10.1126/science.1248361

Helms, H., Kräck, J., 2016. Energy savings by light-weighting- 2016 Update.

Helms, H., Lambrecht, U., 2004. Energy savings by light-weighting - II Final report. Heidelberg.

Helms, H., Lambrecht, U., Höpfner, U., 2003. Energy savings by light-weighting.

Hubbard, B.R.S., Beck, E.C., 2016. Weight reduction 783-789.

ISO, 2006. ISO 14040:2006 - Environmental management -- Life cycle assessment -Principles and framework [WWW Document]. URL https://www.iso.org/standard/37456.html (accessed 7.13.17).

Kamakaté, F., Schipper, L., 2009. Trends in truck freight energy use and carbon emissions in selected OECD countries from 1973 to 2005. Energy Policy 37, 3743-3751. doi:10.1016/j.enpol.2009.07.029

Kashian, R., Pagel, J., Brannon, I., 2017. The Jones Act in Perspective: A survey of the costs and effects of the 1920 Merchant Marine Act [WWW Document]. Grassroot Inst. Hawaii. URL http://www.grassrootinstitute.org/2017/04/the-jones-act-in-perspective/ (accessed 8.17.17).

Kim, H.C., Wallington, T.J., 2013. Life Cycle Assessment of Vehicle Lightweighting: A Physics-Based Model to Estimate Use-Phase Fuel Consumption of Electrified Vehicles. Environ. Sci. Technol. 47, 14358-14366. doi:10.1021/acs.est.6b02059

Kim, H.C., Wallington, T.J., Sullivan, J.L., Keoleian, G.A., 2015. Life Cycle Assessment of Vehicle Lightweighting: Novel Mathematical Methods to Estimate Use-Phase Fuel Consumption. Environ. Sci. Technol. 49, 10209-10216. doi:10.1021/acs.est.5b01655

Legal Information Institute, 2009. 46 U.S. Code $§ 50101$ - Objectives and policy [WWW Document]. URL https://www.law.cornell.edu/uscode/text/46/50101 (accessed 8.17.17).

MAN Diesel \& Turbo, 1998. Basic Principles of Ship Propulsion. Elsevier Ocean Eng. Ser. 1. doi:10.1017/CBO9781107415324.004

MarineTraffic, 2017. Voyage planner - Distance calculator [WWW Document]. URL https://www.marinetraffic.com/en/voyage-planner (accessed 6.13.17).

McKinnon, A.C., 1999. A Logistical Perspective on the Fuel Efficiency of Road Freight 
Transport.

Meyer, J., Stahlbock, R., Voß, S., 2012. Slow steaming in container shipping, in: 2012 45th Hawaii International Conference on System Sciences. pp. 1306-1314. doi:10.1109/HICSS.2012.529

Morris, D., 2015. Mississippi River vital to U.S. global shipping competitiveness [WWW Document]. Fortune. URL http://fortune.com/2015/05/12/mississippi-river-21st-century/ (accessed 8.17.17).

Nahlik, M.J., Kaehr, A.T., Chester, M. V., Horvath, A., Taptich, M.N., 2016. Goods Movement Life Cycle Assessment for Greenhouse Gas Reduction Goals. J. Ind. Ecol. 20, 317-328. doi:10.1111/jiec. 12277

National Renewable Energy Laboratory, 2005. U.S. Life Cycle Inventory Database [WWW Document]. URL https://www.lcacommons.gov/nrel/search (accessed 8.1.11).

National Renewable Energy Laboratory, 2004. U.S. Life Cycle Inventory Database [WWW Document]. URL https://www.lcacommons.gov/nrel/search (accessed 8.1.11).

National Renewable Energy Laboratory, 2000. U.S. Life Cycle Inventory Database [WWW Document]. URL https://www.lcacommons.gov/nrel/search (accessed 8.1.11).

Odhams, A.M.C., Roebuck, R.L., Lee, Y.J., Hunt, S.W., Cebon, D., 2010. Factors influencing the energy consumption of road freight transport. Proc. Inst. Mech. Eng. Part C J. Mech. Eng. Sci. 224, 1995-2010. doi:10.1243/09544062JMES2004

Office of Energy Efficiency \& Renewable Energy, 2011. Fact \#671: April 18, 2011 Average Truck Speeds | Department of Energy [WWW Document]. URL https://energy.gov/eere/vehicles/fact-671-april-18-2011-average-truck-speeds (accessed 8.7.17).

Pennington, D.W., Potting, J., Finnveden, G., Lindeijer, E., Jolliet, O., Rydberg, T., Rebitzer, G., 2004. Life cycle assessment Part 2: Current impact assessment practice. Environ. Int. 30, 721-739. doi:10.1016/j.envint.2003.12.009

Pietzcker, R.C., Longden, T., Chen, W., Fu, S., Kriegler, E., Kyle, P., Luderer, G., 2014. Longterm transport energy demand and climate policy: Alternative visions on transport decarbonization in energy-economy models. Energy 64, 95-108. doi:10.1016/j.energy.2013.08.059

Prucz, J.C., Shoukry, S.N., William, G.W., Shoukry, M.S., 2013. Lightweight Composite Materials for Heavy Duty Vehicles.

Ramanathan, R., 2000. A holistic approach to compare energy efficiencies of different transport modes. Energy Policy 28, 743-747.

Ramanathan, V., Feng, Y., 2009. Air pollution, greenhouse gases and climate change: Global and regional perspectives. Atmos. Environ. 43, 37-50. doi:10.1016/j.atmosenv.2008.09.063

Rodrigue, J.-P., Comtois, C., Slack, B., 2017. The Geography of Transport Systems. Hofstra University, Department of Global Studies \& Geography.

Scelsi, L., Bonner, M., Hodzic, A., Soutis, C., Wilson, C., Scaife, R., Ridgway, K., 2011. Potential emissions savings of lightweight composite aircraft components evaluated through life cycle assessment. Express Polym. Lett. 5, 209-217. doi:10.3144/expresspolymlett.2011.20

Schipper, L., Scholl, L., Price, L., 1997. Energy use and carbon emissions from freight in 10 industrialized countries: An analysis of trends from 1973 to 1992. Transp. Res. Part D Transp. Environ. 2, 57-76. doi:10.1016/S1361-9209(96)00014-4 
Sea-Distances, 2017. Distances [WWW Document]. URL https://sea-distances.org/ (accessed 6.13.17).

Slack, B., Comtoise, C., Wiegmans, B., Witte, P., 2017. (in press). Ships time in port, International Journal of Shipping and Transport Logistics.

Spielmann, M., Scholz, R.W., 2005. Life Cycle Inventories of Transport Services. Int. J. Life Cycle Assess. 10, 85-94.

Steinecker Containerhandel, 2012. Technical Specification for a Typical Steel Dry cargo Container 20'x8'x8'6" Type "Side Door" 0-18.

Sullivan, J.L., Lewis, G.M., Keoleian, G.A., 2018. Effect of Mass on Multimodal Fuel Consumption in Moving People and Freight in the U.S. Transp. Res. Part D Transp. Environ. 63, 786-808. doi:https://doi.org/10.1016/j.trd.2018.06.019

Theofanis, S., Boile, M., 2009. Empty marine container logistics: Facts, issues and management strategies. GeoJournal 74, 51-65. doi:10.1007/s10708-008-9214-0

U.S. Army Corps of Engineers, 2016. U.S. Waterborne Container Traffic by Port/Waterway in $2015 \quad$ [WWW Document]. URL http://www.navigationdatacenter.us/wcsc/by_porttons15.html (accessed 6.16.17).

U.S. Automotive Materials Partnership, Ecobalance, National Pollution Prevention Center, 1999. Life Cycle Inventory Analysis of a Generic Vehicle, USAMP LCA Special Topics Group.

U.S. DOT, 2017. National Transportation Statistics | Bureau of Transportation Statistics [WWW

Document].

URL https://www.rita.dot.gov/bts/sites/rita.dot.gov.bts/files/publications/national_transportati on_statistics/index.html\#chapter_4 (accessed 5.18.17).

U.S. DOT, 2014. Freight Facts and and Figures 2013.

U.S. Energy Information Administration, 2017a. Monthly Energy Review (July 2017).

U.S. Energy Information Administration, 2017b. U.S. refiner residual fuel oil prices.

U.S. Energy Information Administration, 2017c. Gasoline and Diesel Fuel Update [WWW Document]. URL https://www.eia.gov/petroleum/gasdiesel/ (accessed 8.16.17).

U.S. Energy Information Administration, 2017d. Annual Energy Outlook http://www.eia.doe.gov/oiaf/aeo/index.html. doi:DOE/EIA-0383(2017)

U.S. EPA, 2017. Sources of Greenhouse Gas Emissions [WWW Document]. URL https://www.epa.gov/ghgemissions/sources-greenhouse-gas-emissions (accessed 7.31.17).

U.S. EPA, 2016. Learn about SmartWay Verified Technologies [WWW Document]. URL https://www.epa.gov/smartway/learn-about-smartway-verified-technologies (accessed 5.18.17).

U.S. EPA, 2015. Inventory of U.S. greenhouse gas emissions and sinks [WWW Document]. URL https://www.epa.gov/ghgemissions/inventory-us-greenhouse-gas-emissions-andsinks (accessed 5.18.17).

U.S. Maritime Administration, 2015. U.S. waterborne container trade in 2015, by trading partner (in TEUs) [WWW Document]. Stat. - Stat. Portal. URL https://www.statista.com/statistics/325013/leading-us-trading-partners-for-containertrade/ (accessed 6.16.17).

UNCTAD, 2015. Estimated containerized cargo flows on major container trade routes in 2015, by trade route (in million TEUs) [WWW Document]. Stat. Stat. Portal. URL https://www.statista.com/statistics/253988/estimated-containerized-cargo-flows-on- 
major-container-trade-routes/ (accessed 6.16.17).

uShip, 2015. Ultimate Freight Guide [WWW Document]. URL http://www.uship.com/ultimate-freight-guide (accessed 5.18.17).

Valentine, H., 2017. Foreign Trade, Transshipment and the Jones Act [WWW Document]. URL http://maritime-executive.com/editorials/foreign-trade-transshipment-and-thejones-act (accessed 8.17.17).

Winebrake, J.J., Corbett, J.J., Falzarano, A., Hawker, J.S., Korfmacher, K., Ketha, S., Zilora, S., 2008. Assessing Energy, Environmental, and Economic Tradeoffs in Intermodal Freight Transportation. J. Air Waste Manage. Assoc. 58, 1004-1013. doi:10.3155/10473289.58.8.1004

World Shipping Council, 2017a. Top 50 World Container Ports [WWW Document]. URL http://www.worldshipping.org/about-the-industry/global-trade/top-50-world-containerports (accessed 6.13.17).

World Shipping Council, 2017b. Global Container Fleet [WWW Document]. URL http://www.worldshipping.org/about-the-industry/containers/global-container-fleet (accessed 6.12.17).

Zanchi, L., Delogu, M., Ierides, M., Vasiliadis, H., 2016. Life Cycle Assessment and Life Cycle Costing as Supporting Tools for EVs Lightweight Design., in: Setchi, R., Howlett, R., Liu, Y., Theobald, P. (Eds.), Sustainable Design and Manufacturing 2016. Smart Innovation, Systems and Technologies. Springer, Cham. doi:10.1007/978-3-319-320984

Zhang, M., Mu, H., Li, G., Ning, Y., 2009. Forecasting the transport energy demand based on PLSR method in China. Energy 34, 1396-1400. doi:10.1016/j.energy.2009.06.032 


\section{Appendix A}

\section{Fuel Consumption and FRV Calculations}

To calculate the fuel consumption and fuel reduction value (FRV) for each mode, several sources of data were used. The following will discuss data and methods used for the truck and train mode, followed by the ship mode.

The data and methods used to determine the truck and train fuel consumption and FRV were adapted from work by Sullivan et al (Sullivan et al., 2018). Table A1 indicates the base values for fuel consumption and FRV for both the truck (class 8 line haul) and freight train. See following subsections for an in-depth discussion of the methods used to calculate these values.

Table A1: Vehicle specifics, fuel consumption, fuel intensity, and FRVs for a wide range of vehicles

\begin{tabular}{|c|c|c|c|c|c|c|c|}
\hline Vehicle & $\mathrm{Mgv}_{\mathrm{g}}^{\mathrm{a}}$ & $M_{p y l d}$ & $M_{v h}^{b}$ & $F_{\text {int }}$ & $\mathrm{FC}$ & FRV & $\begin{array}{c}\text { Drive/Duty } \\
\text { Cycles }\end{array}$ \\
\hline & $\begin{array}{l}\text { Short } \\
\text { Tons }\end{array}$ & $\begin{array}{l}\text { Short } \\
\text { Tons }\end{array}$ & $\begin{array}{l}\text { Short } \\
\text { Tons }\end{array}$ & $\begin{array}{l}\mathrm{Gal} / 100 \\
\text { ton-miles }\end{array}$ & $\begin{array}{l}\mathrm{Gal} / 100 \\
\text { mile }\end{array}$ & $\begin{array}{l}\mathrm{Gal} / 100 \\
\text { ton-miles }\end{array}$ & \\
\hline Class 8 line haul ${ }^{\mathrm{c}}$ & 40 & 22.7 & 17.3 & 0.85 & 19.2 & 0.238 & HHDDT65 \\
\hline Freight train ${ }^{\mathrm{d}}$ & 7,175 & 4,100 & 3,074 & 0.18 & 746 & 0.045 & 40 CFR 1033.530 \\
\hline
\end{tabular}

${ }^{a}$ This is the maximum operating mass as specified by the manufacturer often referred to gross vehicle mass; ${ }^{b}$ This is the vehicle mass without passengers or payload which for vehicles on tires is curb weight (mass); ${ }^{\mathrm{c}}$ (Delorme et al., 2009); ${ }^{\mathrm{d}}$ acceleration not included

\section{$\underline{\text { Truck }}$}

Fuel consumption for wheeled vehicles (FC) can be described by the following equations:

$$
\begin{gathered}
F C=F C_{M}+F C_{\text {aero }}+F C_{a c c}+F C_{f}+F C_{l} \\
F C=F R V \cdot M+\gamma
\end{gathered}
$$


where $F C_{i}$ refers to fuel consumption of a variety of components ( $M$ is mass, aero is aerodynamic resistance, $a c c$ is accessory loading, $f$ is mechanical losses due to engine friction and pumping, and $l$ is other miscellaneous powertrain losses), $\gamma$ denotes all non-mass related terms from equation $\mathrm{A} 1$, and $F R V$ is the fuel reduction value of the vehicle. Equations $\mathrm{A} 1$ and A2 indicate that fuel consumption can be broken down into multiple components, only one of which is related to moving the mass of the vehicle. Each of the terms in equation A1 can be calculated by integrating over a drive cycle and a power consumption expression for moving the vehicle, as demonstrated by Kim et al (Kim et al., 2015; Kim and Wallington, 2013). The fuel consumption determined by Sullivan et al. assumed that the container on the truck was fully loaded, while our study assumed that the container was loaded to 7 tonnes (or 7.714 short tons). To account for this, the fuel consumption reported by Sullivan et al. was altered using equation $\mathrm{A} 3$.

$$
F C_{7 M T}=F C_{f u l l}-\left(M_{f u l l}-M_{7 M T}\right) \times F R V
$$

The complete calculation of the final value of truck fuel consumption used in our study (36.8 $\mathrm{L} / 100 \mathrm{~km}$ ) was then:

$$
\begin{gathered}
F C_{7 M T}=19.2 \frac{g a l}{100 \mathrm{mi}}-(22.7 \text { tons }-7.714 \text { tons }) * 0.238 \frac{\mathrm{gal}}{100 \mathrm{ton}-\mathrm{mi}} \\
=15.6 \frac{\mathrm{gal}}{100 \mathrm{mi}}=36.8 \frac{\mathrm{L}}{100 \mathrm{~km}}
\end{gathered}
$$


To calculate the truck FRV, equation A2 as well as equations A4 and A5 were used, where Dst refers to the duty cycle distance, $\eta_{i}$ is engine efficiency, $\eta_{t}$ is transmissions efficiency, $t$ is time, and $H_{f}$ is fuel lower heating value.

$$
\begin{gathered}
F R V=F C_{M} /(M \cdot D s t) \\
F C_{M}=\frac{1}{H_{f} \eta_{i} \eta_{t}} \int\left(A v+B v^{2}+a v M\right) \cdot d t
\end{gathered}
$$

Coefficients for these equations can be obtained through a variety of methods, including certification data, fuel consumption vs. mass data, or computer simulation. The truck FRV used in our study ( $0.238 \mathrm{gal} / 100$ ton-mi) was based on work completed by Sullivan et al. based on computer simulation data provided in a report prepared for the National Academy of Sciences analyzing the fuel consumption trends of medium and heavy duty vehicles (Delorme et al., 2009).

\section{$\underline{\text { Train }}$}

Sullivan et al. indicated that the fuel consumption for trains can be computed using equation A6.

$$
F C=\int\left(\Sigma R_{i}+a\right) \cdot v \cdot d t /\left\{\eta_{i} \cdot \eta_{t} \cdot H_{f} \cdot D s t\right\} \quad \text { Eq. A6 }
$$

where $R$ refers to the train running resistance, which is defined in equation A7.

$$
R=A+B \cdot v+C \cdot v^{2}
$$

The coefficients $A, B$, and $C$ represent a multitude of resistances. $A$ represents journal bearing, rolling, and track resistances, $B$ represents flange friction, flange impact, rail rolling friction, and rail wave action, and $C$ represents head wind pressure, rear drag, skin resistance, 
and yaw angle of wind tunnels. They can be determined empirically through coast-down tests. Once $R$ was known and a train duty cycle was selected, the fuel consumption could be calculated using equation A6.

Based on this method, Sullivan et al. concluded that the train FRV was 0.045 gal/100 ton-mi. The fuel consumption for a fully loaded train was determined to be 746 gal/100 mi. Our study assumed that, as with the truck mode, the containers on the train were not fully loaded, but loaded to 7 metric tonnes, or 7.714 short tons. Equation A3 was again used to determine the fuel consumption for the train, assuming the containers were loaded to 7 metric tonnes, as shown in the calculation below, resulting in a train fuel consumption estimate of $1,484 \mathrm{~L} / 100$ $\mathrm{km}$.

$$
\begin{gathered}
F C_{7 M T}=746 \frac{g a l}{100 \mathrm{mi}}-(4,100 \text { tons }-1,542.8 \text { tons }) * 0.045 \frac{\mathrm{gal}}{100 \text { ton }-\mathrm{mi}} \\
=630.9 \frac{\mathrm{gal}}{100 \mathrm{mi}}=1,484 \frac{\mathrm{L}}{100 \mathrm{~km}}
\end{gathered}
$$

\section{$\underline{\text { Ship }}$}

The data used to calculate the ship fuel consumption and FRV were sourced from a report published by the American Bureau of Shipping (ABS), and are collected in Table A2 (ABS, 2013). According to ABS, the data were collected from a variety of sources, including vendors and manufacturers, industry reports, and experts (2013). The speed of the ship was determined based on a report by MAN Diesel \& Turbo, in which average ship speed at an assumed $90 \%$ maximum engine power was calculated for a variety of ship capacities (MAN Diesel \& Turbo, 1998). 
Table A2: Percent fuel savings for a 1\% change in hull mass for a variety of ship capacities (ABS, 2013)

\begin{tabular}{|l|c|c|c|c|c|}
\hline & $\begin{array}{c}1,000 \\
\text { (Feeder-ship) }\end{array}$ & $\begin{array}{c}4,500 \text { TEU } \\
\text { (Panamax) }\end{array}$ & $\begin{array}{c}4,500 \text { TEU } \\
\text { (Neo- } \\
\text { Panamax) }\end{array}$ & $\begin{array}{c}8,000 \text { TEU } \\
\text { (Post- } \\
\text { Panamax) }\end{array}$ & $\begin{array}{c}12,500 \text { TEU } \\
\text { (Ultra } \\
\text { Large) }\end{array}$ \\
\hline $\begin{array}{l}1 \% \text { Reduction in Hull } \\
\text { Steel (tonnes) }\end{array}$ & 50 & 191 & 191 & 318 & 471 \\
\hline $\begin{array}{l}\% \text { Change in Fuel } \\
\text { Consumption for } 1 \% \\
\text { Change in Steel } \\
\text { Weight }\end{array}$ & $0.32 \%$ & $0.23 \%$ & $0.26 \%$ & $0.25 \%$ & $0.24 \%$ \\
\hline $\begin{array}{l}\text { Tonnes/day Fuel } \\
\text { Consumption for } \\
\text { Standard Ship }\end{array}$ & 31.3 & 144.4 & 157.8 & 223.3 & 286.7 \\
\hline $\begin{array}{l}\text { Savings (tonnes/day) } \\
\text { for 1\% Reduction in } \\
\text { Steel Weight }\end{array}$ & 0.10 & 0.33 & 0.41 & 0.55 & 0.70 \\
\hline
\end{tabular}

The fuel consumption of the 4,500 TEU ship used in this study was determined by first averaging the ABS reported fuel consumption (in tonnes/day) of the two 4,500 TEU ships (Panamax and Neo-Panamax). Then the fuel consumption in tonnes/day was converted to L/100 km as follows, using an assumed speed of 24.5 knots:

$$
\begin{gathered}
F C_{\text {avg } 4,500}=\frac{144.4 \frac{\text { tonnes }}{\text { day }}+157.8 \frac{\text { tonnes }}{\text { day }}}{2}=151.1 \frac{\text { tonnes }}{\text { day }} \\
F C_{\text {avg } 4,500}=151.1 \frac{\text { tonnes }}{\text { day }} \times \frac{1,000 \mathrm{~kg}}{1 \text { tonne }} \times \frac{1 \text { day }}{24 \mathrm{hr}} \times \frac{1.009 \mathrm{~L}}{\mathrm{~kg}}=6,352.5 \mathrm{~L} / \mathrm{hr} \\
F C_{\text {avg } 4,500}=\frac{6,352.5 \frac{\mathrm{L}}{\mathrm{hr}}}{\left(24.5 \mathrm{knots} \times \frac{1.852 \frac{\mathrm{km}}{\mathrm{hr}}}{\mathrm{knot}}\right)}=14,000 \frac{\mathrm{L}}{100 \mathrm{~km}}
\end{gathered}
$$

To determine the ship FRV, data from the ABS report was used. From the ABS report, the change in mass for five sizes of container ships was known in tonnes. To determine the change in fuel consumption for each of the container ships, the savings in tonnes/day 
reported by ABS were used. The savings in tonnes/day were first converted to $\mathrm{L} / \mathrm{hr}$, and then the speed at which the container ship was assumed to be traveling ( 24.5 knots) was divided out to convert into $\mathrm{L} / \mathrm{km}$. The change in mass (191 tonnes for both ships) was then divided out of the value, which was then multiplied by 100 to yield the final results in units of L/100 tonn-km. The calculations completed for the two 4,500 TEU ships (Panamax and NeoPanamax) are included below.

$$
\begin{aligned}
F R V_{\text {Panamax }} & \left.=\frac{\left(\frac{\left(0.33 \frac{\text { tonnes }}{\text { day }} \times \frac{1000 \mathrm{~kg}}{\text { tonne }} \times \frac{1 \mathrm{day}}{24 \mathrm{hr}} \times \frac{1.009 \mathrm{~L}}{\mathrm{~kg}}\right)}{24.5 \mathrm{knots} \times \frac{1.852 \frac{\mathrm{km}}{\mathrm{hr}}}{\mathrm{knot}}}\right)}{191 \text { tonnes }}\right) \\
& =0.160 \frac{\mathrm{L} \frac{\mathrm{k}}{100 \text { tonne }-\mathrm{km}}}{24.5 \mathrm{knots} \times \frac{\mathrm{knot}}{\mathrm{hr}}} \\
F R V_{\text {Neo-Panamax }} & =\frac{\left(\frac{\left(0.41 \frac{\text { tonnes }}{\text { day }} \times \frac{1000 \mathrm{~kg}}{\text { tonne }} \times \frac{1 \mathrm{day}}{24 \mathrm{hr}} \times \frac{1.009 \mathrm{~L}}{\mathrm{~kg}}\right)}{191 \text { tonnes }}\right)}{=0.199 \frac{\mathrm{L}}{100 \text { tonne }-\mathrm{km}}}
\end{aligned}
$$

For the purpose of this study, the two Fuel Reduction Values for the 4,500 TEU container ships were averaged, as demonstrated below.

$$
\begin{aligned}
F R V_{\text {avg } 4,500}= & \frac{0.160 \frac{L}{100 \text { tonne }-\mathrm{km}}+0.199 \frac{\mathrm{L}}{100 \text { tonne }-\mathrm{km}}}{2} \\
& =0.179 \frac{\mathrm{L}}{100 \text { tonne }-\mathrm{km}}
\end{aligned}
$$




\section{Uncertainty Analysis: Monte Carlo Analysis}

To quantify the effect of parameter uncertainty on our results, Monte Carlo simulations were completed for the five main analyses conducted. For each input variable in which uncertainty was identified, 10,000 trials were run with input values varied randomly between minimum and maximum expected values with the value used in our deterministic model identified as "most likely," assuming a triangular distribution. The relevant output values were then determined for each of the 10,000 trials, and the resulting output distribution was compared to the results from our deterministic model. The following sections describe the uncertainty in our calculated results for fuel consumption, a single container's life cycle energy demand, the national fleet life cycle energy demand, the global fleet life cycle energy demand, and case studies.

\section{Container Driven Fuel Consumption}

Modal fuel consumption that is driven by the mass of lightweighted containers was used to calculate reduction in environmental burdens due to lightweighting. To determine the fuel consumption for each of the lightweighted vehicles, the mass of the container (conventional or lightweighted) was multiplied by the modal FRV, as in Equation 1. While the FRV for each of the modes used in the calculations was determined based on a thorough literature review, other reasonable FRVs are reported in literature for truck, train, and ship. This FRV variability results in uncertainty in the fuel consumption estimated for each of the modes. Based on Helms and Kräck, the FRV for a freight truck could range from $0.49 \mathrm{~L} / 100$ tonne-km to $0.65 \mathrm{~L} / 100$ tonne-km based on duty cycle, assuming highway driving (2016). The truck FRV used in this study was $0.617 \mathrm{~L} / 100$ tonne-km. The train FRV could be as low as $0.09 \mathrm{~L} / 100$ tonne-km (Helms et al., 2003), or could be as high as $0.272 \mathrm{~L} / 100$ tonne-km taking into account effects 
of acceleration (Sullivan et al., 2018). The train FRV used was $0.117 \mathrm{~L} / 100$ tonne-km and so the uncertainty results will not be centered around the results from our deterministic model. The ship FRV varied between $0.118 \mathrm{~L} / 100$ tonne-km and $0.245 \mathrm{~L} /$ tonne-km, with the deterministic value used being $0.179 \mathrm{~L} / 100$ tonne-km. The uncertainty in ship FRV was based on the effect of container ship size on FRV. The lowest FRV is for an 18,000 TEU container ship and the highest FRV is for a 1,000 TEU container ship (ABS, 2013). Figure A1 illustrates the results of a Monte Carlo simulation of the modal fuel consumption values for each lightweighting scenario.

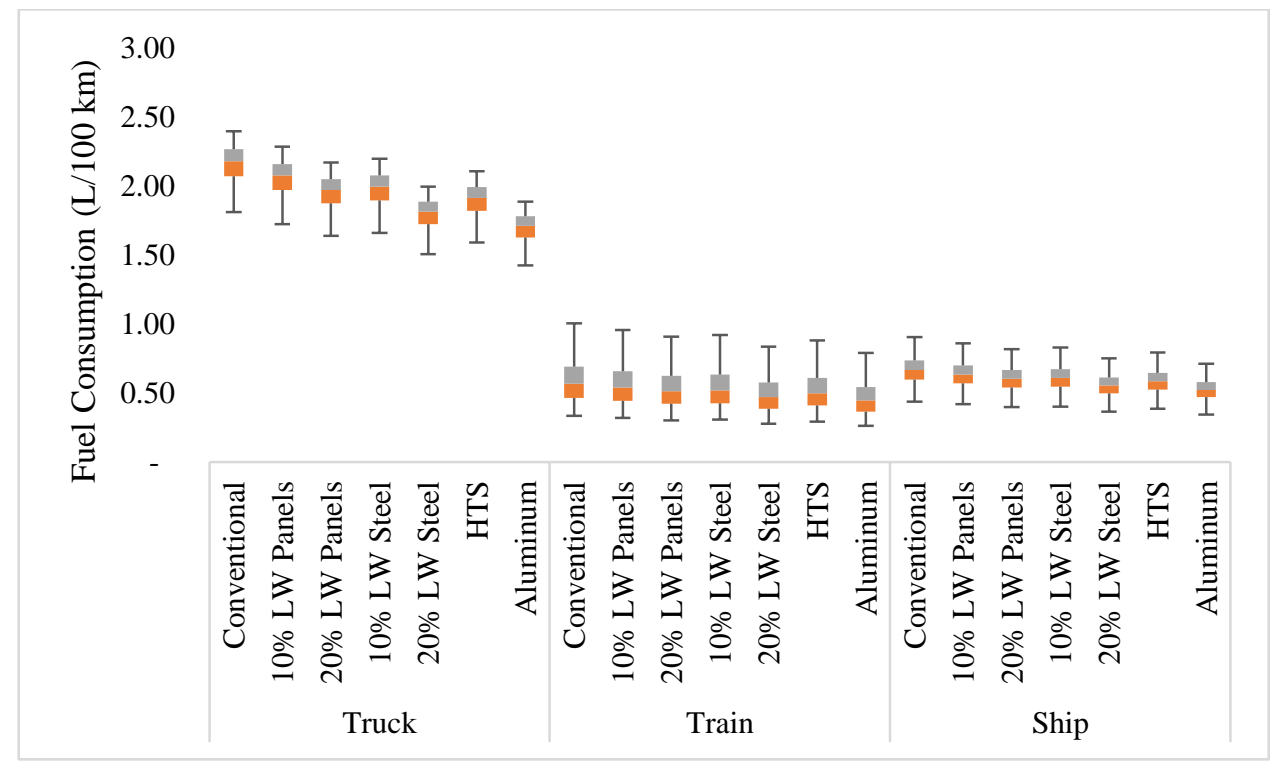

Figure Al Monte Carlo Single Container Fuel Consumption. Monte Carlo results for modal fuel consumption driven by container mass. The uncertainty results of the different lightweighting scenarios should be compared to each other by percentile. For instance, the $75^{\text {th }}$ percentile fuel consumption of the conventional should be compared to the $75^{\text {th }}$ percentile fuel consumption of any of the lightweighting scenarios.

Based on Figure A1, the container-driven fuel consumption for the truck will have a minimum value ranging from $1.42 \mathrm{~L} / 100 \mathrm{~km}$ to $1.81 \mathrm{~L} / 100 \mathrm{~km}$ depending on the lightweighting scenario, and a maximum value ranging from $1.88 \mathrm{~L} / 100 \mathrm{~km}$ to $2.40 \mathrm{~L} / 100 \mathrm{~km}$. The mean of the Monte Carlo simulation for the truck ranges from $1.70 \mathrm{~L} / 100 \mathrm{~km}$ to $2.16 \mathrm{~L} / 100 \mathrm{~km}$ depending on the lightweighting scenario, which is similar to the originally calculated range of $1.79 \mathrm{~L} / 100 \mathrm{~km}$ 
to $2.28 \mathrm{~L} / 100 \mathrm{~km}$. This indicates that the uncertainty in FRV will not significantly affect the fuel consumption results. Depending on the lighweighting scenario, the minimum train fuel consumption value estimated in the Monte Carlo simulation ranged from $0.26 \mathrm{~L} / 100 \mathrm{~km}$ to $0.33 \mathrm{~L} / 100 \mathrm{~km}$, and the maximum value ranged from $0.79 \mathrm{~L} / 100 \mathrm{~km}$ to $1.00 \mathrm{~L} / 100 \mathrm{~km}$, with a mean range of $0.46 \mathrm{~L} / 100 \mathrm{~km}$ to $0.59 \mathrm{~L} / 100 \mathrm{~km}$. The originally calculated train fuel consumption value ranged from $0.34 \mathrm{~L} / 100 \mathrm{~km}$ to $0.43 \mathrm{~L} / 100 \mathrm{~km}$. Uncertainty in ship fuel consumption is less pronounced, with minimum values ranging from $0.34 \mathrm{~L} / 100 \mathrm{~km}$ to 0.44 $\mathrm{L} / 100 \mathrm{~km}$, maximum values ranging from 0.71 to $0.90 \mathrm{~L} / 100 \mathrm{~km}$, and the mean Monte Carlo value ranging from $0.52 \mathrm{~L} / 100 \mathrm{~km}$ to $0.67 \mathrm{~L} / 100 \mathrm{~km}$, depending on the lightweighting scenario. The originally calculated ship fuel consumption ranged from $0.52 \mathrm{~L} / 100 \mathrm{~km}$ to $0.66 \mathrm{~L} / 100 \mathrm{~km}$. The uncertainty results of the different lightweighting scenarios should be compared to each other by percentile. For instance, the $75^{\text {th }}$ percentile conventional container energy demand should be compared to the $75^{\text {th }}$ percentile energy demand of any of the lightweighting scenarios.

\section{$\underline{\text { Single Container Life Cycle Energy Demand }}$}

The life cycle energy consumption and GHG emissions of a single container are driven by modal fuel consumption as well as assumed lifetime distances traveled by each mode. As discussed in the previous section, modal fuel consumption is affected by the FRV of the vehicle. The range in truck, train, and ship FRVs used in the Monte Carlo analysis of single container life cycle burdens was the same as for the modal fuel consumption Monte Carlo trials. The original lifetime distance of a container traveling on a truck was assumed to be $1,086,000 \mathrm{~km}$, with a minimum of $886,300 \mathrm{~km}$ (Davis et al., 2016), and a maximum of 1,445,900 km (U.S. DOT, 2014). The train lifetime distance was originally assumed to be 
$55,820 \mathrm{~km}$, though the train lifetime distance could be as small as 24,251 km (U.S. Energy Information Administration, 2017d) or as large as 3,360,734 km (U.S. DOT, 2017, 2014). Lastly, the ship lifetime distance range was estimated to be from $820,000 \mathrm{~km}$ (assuming a container spends $16 \%$ of its life on a ship) to $6,667,200 \mathrm{~km}$ (Helms and Lambrecht, 2004). The ship lifetime distance used in the original calculations of the study was 4,201,414 km. Figure A2 illustrates the results of Monte Carlo simulations ( $\mathrm{n}=10,000$ trials) conducted for each lighweighting scenario of the single container life cycle energy demand results.

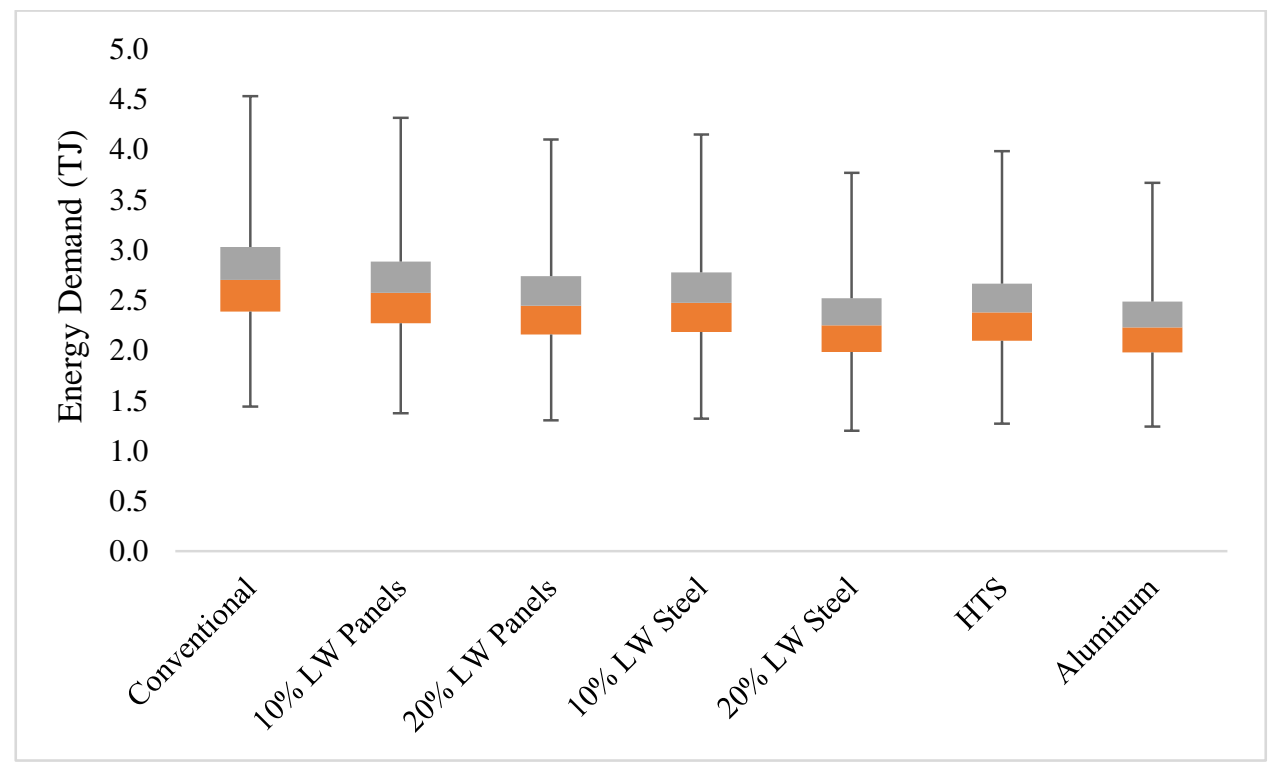

Figure A2 Monte Carlo Single Container Life Cycle Energy Demand. Monte Carlo results for single container life cycle energy demand. The uncertainty results of the different lightweighting scenarios should be compared to each other by percentile. For instance, the $75^{\text {th }}$ percentile energy demand of the conventional should be compared to the $75^{\text {th }}$ percentile energy demand of any of the lightweighting scenarios.

The original life cycle energy demand ranged from $2.57 \mathrm{TJ}$ for the conventional container to $2.12 \mathrm{TJ}$ for the aluminum replacement scenario. Figure A2 indicates that life cycle energy demand for the aluminum replacement scenario could be as low as $1.24 \mathrm{TJ}$ or as high as 3.67 TJ, with a mean of $2.24 \mathrm{TJ}$. The conventional container has a life cycle energy demand between 1.44 TJ and 4.53 TJ, with a mean value of $2.72 \mathrm{TJ}$. It is evident that the Monte Carlo results are generally higher than the originally calculated values. This is primarily driven by the 
slightly skewed maximum values for the inputs, especially train lifetime distance. The reduction in mean burdens in the Monte Carlo simulation remains similar to the reduction in burdens originally calculated- the aluminum replacement scenario results in a $17 \%$ reduction in energy and emissions based on the mean Monte Carlo results. GHG emissions follow the same trend as life cycle energy demand, with minimum values ranging from 96 tonnes $\mathrm{CO}_{2} \mathrm{e}$ to 115 tonnes $\mathrm{CO}_{2} \mathrm{e}$ depending on the lightweighting scenario, and maximum values ranging from 295 tonnes $\mathrm{CO}_{2} \mathrm{e}$ to 368 tonnes $\mathrm{CO}_{2} \mathrm{e}$. As described in the main body of the text, the Monte Carlo calculations were conducted so that the level of uncertainty was consistent between the different lightweighting scenarios, meaning, for example, that the $75^{\text {th }}$ percentile energy demand of the conventional should be compared to the $75^{\text {th }}$ percentile energy demand of any of the lightweighting scenarios.

\section{$\underline{\text { National Fleet Life Cycle Energy Demand }}$}

Similar to the single container life cycle energy demand and GHG emissions, modal FRV and lifetime distances directly affect the life cycle energy demand of the U.S. shipping container fleet. The same input ranges specified above for truck and train FRV and lifetime distance were used in the national fleet life cycle Monte Carlo simulations. There is also uncertainty in the estimated number of containers being transported around the United States. It was originally assumed that $1,180,581$ forty-foot containers were in circulation (either on truck or train) at one time in the U.S., based on a proportional calculation between world fleet size and traffic and U.S. traffic. Other sources of data were not available to compare this fleet size to, and so to establish a range for the Monte Carlo simulation, the number of containers assumed to be in circulation in the U.S. was halved for the minimum input and doubled for the maximum input. 
Figure A3 illustrates the results of the Monte Carlo simulations ( $n=10,000$ trials) conducted for each lightweighting scenario at the national fleet level.

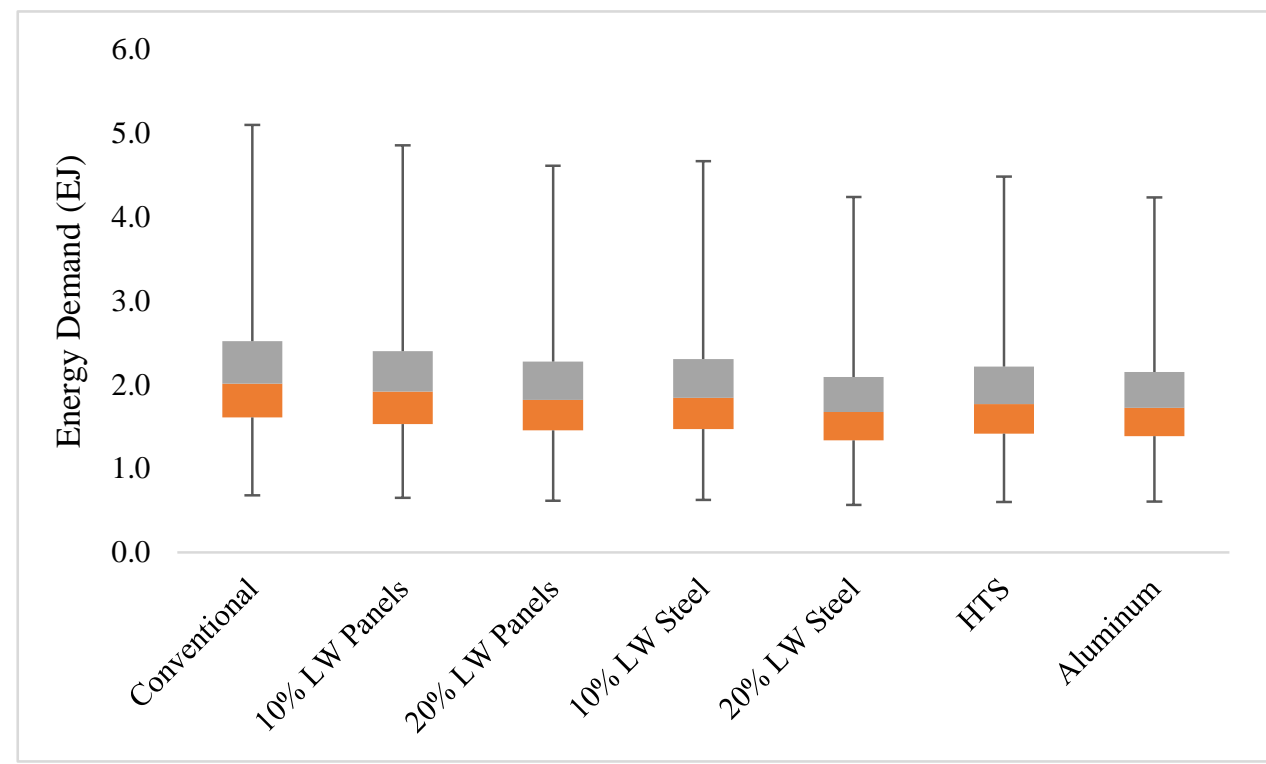

Figure A3 Monte Carlo U.S. Container Fleet Life Cycle Energy Demand. Monte Carlo results for U.S. shipping container fleet life cycle energy demand. The uncertainty results of the different lightweighting scenarios should be compared to each other by percentile. For instance, the $75^{\text {th }}$ percentile energy demand of the conventional should be compared to the $75^{\text {th }}$ percentile energy demand of any of the lightweighting scenarios.

The original life cycle energy demand for the U.S. fleet of containers ranged from $1.54 \mathrm{EJ}$ for the conventional container to 1.28 EJ for the $20 \%$ steel lightweighting scenario. Based on the Monte Carlo simulations, life cycle energy demand for the $20 \%$ steel lighweighting scenario varied from $0.56 \mathrm{EJ}$ to $4.24 \mathrm{EJ}$, with a mean of $1.75 \mathrm{EJ}$. The conventional container has a life cycle energy demand between $0.68 \mathrm{EJ}$ and 5.10 EJ, with a mean value of 2.10 EJ. It is evident that the Monte Carlo results are generally higher than the originally calculated results. This is primarily driven by the skewed maximum values for the inputs, especially for train lifetime distance. While uncertainty in the results alters the absolute differences between the conventional and lightweighted fleet, the percentage reduction in burdens remains the same, with $20 \%$ steel lightweighting resulting in a $17 \%$ reduction in mean burdens estimated in the Monte Carlo analysis. The uncertainty in GHG emissions follows the same trend as energy 
demand, with minimum values estimated through Monte Carlo simulations ranging from 45 million tonnes $\mathrm{CO}_{2} \mathrm{e}$ to 54 million tonnes $\mathrm{CO}_{2} \mathrm{e}$, and maximum values ranging from 333 million tonnes $\mathrm{CO}_{2} \mathrm{e}$ to 400 million tonnes $\mathrm{CO}_{2} \mathrm{e}$.

\section{Global Fleet Life Cycle Energy Demand}

For the global fleet life cycle analysis, only the ship mode was considered, due to lack of reliable truck and train data at a global scale. Uncertainty in the ship FRV and lifetime distance will influence the global energy demand and GHG results, as will the number of assumed fortyfoot containers in the global fleet. The same FRV input range for the ship was used as for the modal fuel consumption and single container life cycle Monte Carlo simulations, however, the original value used for ship lifetime distance for the global calculations differed from that used in the single container life cycle analysis. This was due to the incorporation of different shipping routes in the lifetime distance calculations for the global fleet than for the single container, which was focused on the U.S. The original lifetime ship distance was $3,578,545$ $\mathrm{km}$, and the range used in the Monte Carlo simulations was from 820,000 km to 6,667,200 km. The original number of containers assumed in the global fleet was $17,500,000$ forty-foot containers, though the global fleet could be as low as 5 million or as high as 36 million (Budget Shipping Containers, 2016). Figure A4 illustrates the results of the Monte Carlo simulations ( $n=10,000$ trials) conducted for each lightweighting scenario at the global scale.

Our initial results indicated that the global fleet life cycle energy demand could range from 21.06 EJ for the conventional container to $17.49 \mathrm{EJ}$ for the $20 \%$ steel lightweighting scenario. Based on the Monte Carlo simulations, life cycle energy demand for the $20 \%$ steel lighweighting scenario could be as low as $2.30 \mathrm{EJ}$ or as high as $66.69 \mathrm{EJ}$, with a mean of 20.24 EJ. The conventional container could have a life cycle energy demand from 2.78 EJ up to 80.20 


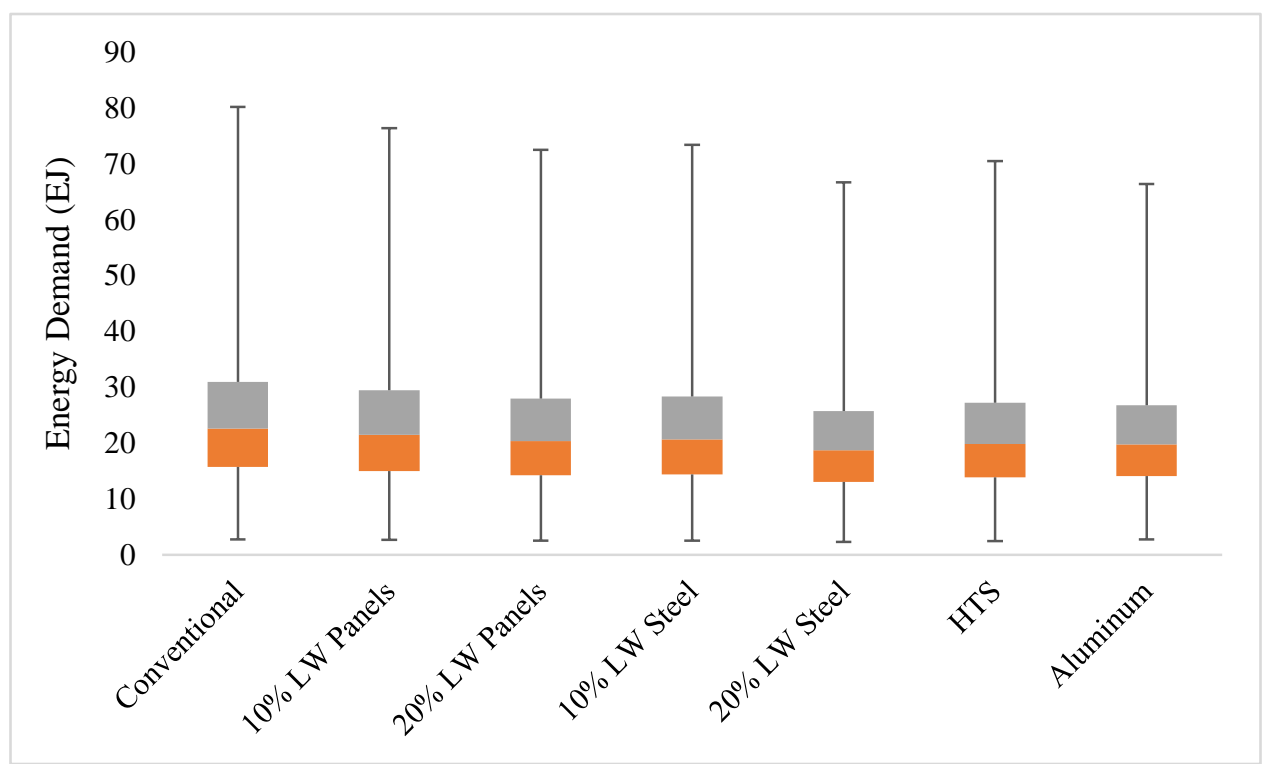

Figure A4 Monte Carlo Global Container Fleet Life Cycle Energy Demand. Monte Carlo results for global shipping container life cycle energy demand. The uncertainty results of the different lightweighting scenarios should be compared to each other by percentile. For instance, the $75^{\text {th }}$ percentile energy demand of the conventional should be compared to the $75^{\text {th }}$ percentile energy demand of any of the lightweighting scenarios.

EJ, with a mean value of 24.37 EJ. The Monte Carlo results are generally higher than the originally calculated values. This is primarily driven by the skewed maximum values for the inputs, as well as the magnitude of the input values, which magnifies uncertainty. Again, while the absolute values reported by the Monte Carlo simulations vary considerably from the originally calculated global fleet life cycle energy demand, the percentage reduction in the burdens through lightweighting align with reported values in this study. Similar to previous results, the Monte Carlo simulations were conducted so that the uncertainty results of the different lightweighting scenarios could be compared to each other by percentile. The uncertainty in GHG emissions follow the same trends as uncertainty in life cycle energy demand with minimum values reported by the Monte Carlo simulations ranging from 0.14 billion tonnes $\mathrm{CO}_{2} \mathrm{e}$ to 0.18 billion tonnes $\mathrm{CO}_{2} \mathrm{e}$, and maximum values ranging from 5.02 billion tonnes $\mathrm{CO}_{2} \mathrm{e}$ to 6.4 billion tonnes $\mathrm{CO}_{2} \mathrm{e}$. 


\section{$\underline{\text { Case Studies }}$}

It was identified that for each of the case study results there was uncertainty in modal FRV, which would influence vehicle fuel consumption, and cargo mass. Table A3 lists the common uncertainty assumptions for each of the case studies. The following sections will list the results of the Monte Carlo simulations for each of the case studies presented in this study.

Table A3: Input values with common uncertainty values in all case studies.

\begin{tabular}{|l|c|c|c|}
\hline & Minimum & Most Likely & Maximum \\
& Value & Value & Value \\
\hline Truck FRV (L/100 tonne-km) & 0.490 & 0.617 & 0.650 \\
\hline Train FRV (L/100 tonne-km) & 0.090 & 0.117 & 0.272 \\
\hline Ship FRV (L/100 tonne-km) & 0.118 & 0.179 & 0.245 \\
\hline Truck and Train Cargo (tonnes) & 0 & 7 & 20.6 \\
\hline
\end{tabular}

\section{Shanghai to Detroit}

In addition to the uncertainty in the variables listed in Table A3, there is uncertainty in distances traveled by each of the modes. The distances were determined from Google Maps and Voyage Planner (MarineTraffic, 2017), and there were often alternative routes suggested. For the case study analyzing the burdens of shipping containers from Shanghai to Detroit, MI through the west coast of the United States, it was assumed that the truck distance could vary from $428 \mathrm{~km}$ to $451 \mathrm{~km}$ (original value: $428 \mathrm{~km}$ ), the train distance could vary from 3,261 $\mathrm{km}$ to $3,442 \mathrm{~km}$ (original value: $3,442 \mathrm{~km}$ ), and the ship distance could vary from $10,843 \mathrm{~km}$ to 
$10,958 \mathrm{~km}$ (original value: 10,985 km). Figure A5 indicates the results of the Monte Carlo uncertainty analysis for this specific case study.

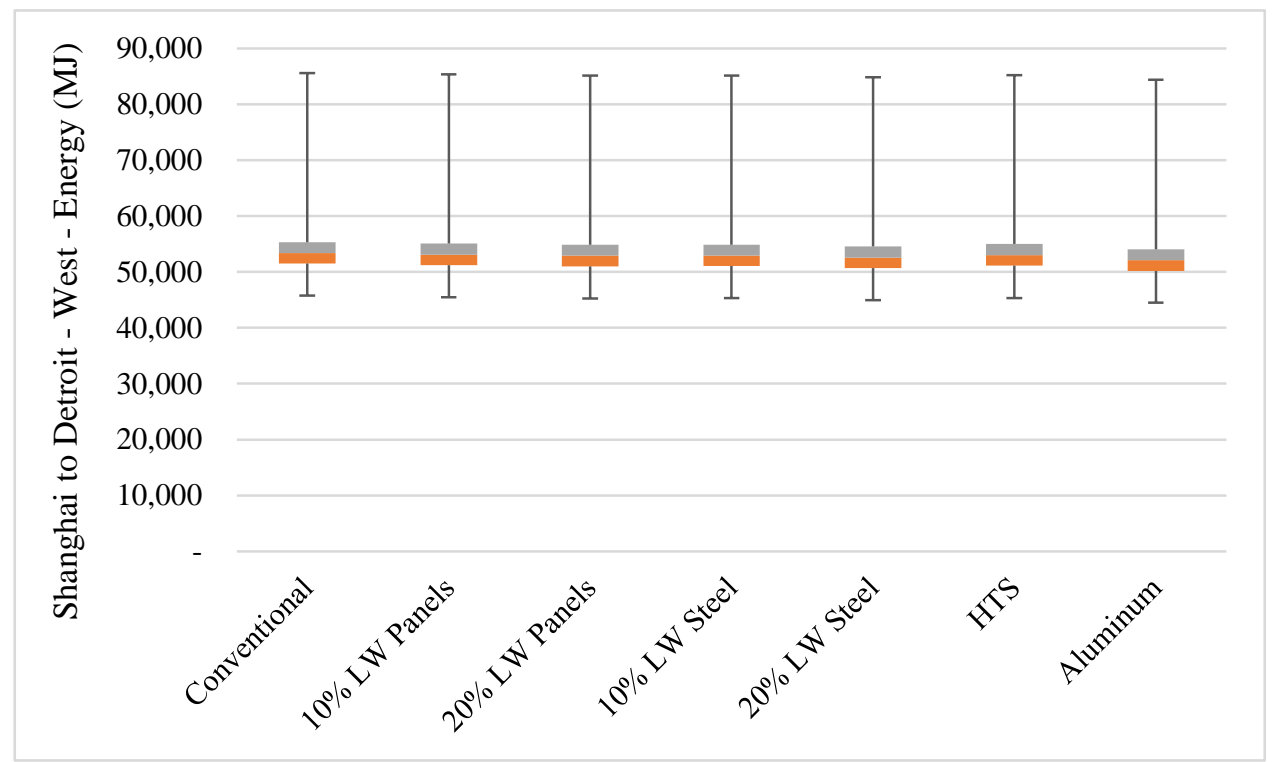

Figure A5 Monte Carlo Shanghai to Detroit (West) Case Study Energy Demand. Monte Carlo results for case study reporting energy required to move containers from Shanghai to Detroit, Michigan, through the west coast of the United States. The uncertainty results of the different lightweighting scenarios should be compared to each other by percentile.

It is evident from Figure A5 that there exists significant uncertainty in the energy demand for this case study, which is due to the significant uncertainty in the modal distances, cargo mass, and overall ship mass. It is apparent from Figure A5 that the inner two quartiles are relatively small, meaning the high values apparent in the fourth quartile are most likely skewed by outliers. The median energy demand of the conventional container in this case study is 53,400 MJ, which drops to 52,100 MJ for the aluminum lightweighting scenario, following the same trend observed in the original deterministic model. The Monte Carlo simulations were again conducted so that the uncertainty results of the different lightweighting scenarios could be compared to each other by percentile. Thus the maximum values of each lightweighting scenario should be compared to each other and to the conventional scenario maximum value, as should the minimum and median values of each scenario be compared. 
Figure A6 demonstrates the Monte Carlo energy demand results for the case study analyzing the burdens of transporting containers from Shanghai through the Panama Canal to Detroit. Similarly to the results presented in Figure A5, there are extreme maximum values resulting from the Monte Carlo simulations due to the large variation in several important input variables, including vehicle fuel consumption and cargo and vehicle masses. It was assumed that the train distance for this trip could vary from $993 \mathrm{~km}$ to $1,032 \mathrm{~km}$ (original value: 993 $\mathrm{km}$ ), and the ship distance could vary from 19,598 $\mathrm{km}$ to $20,892 \mathrm{~km}$ (original value: 19,598 $\mathrm{km})$. The small width of the inner two quartiles in Figure A6 indicates that $50 \%$ of the values will fall within a small range and is thus most representative of the uncertainty. It is clear from the Monte Carlo results that the median value of the conventional container is $65,400 \mathrm{MJ}$, which is reduced to $64,300 \mathrm{MJ}$ for the aluminum lightweighting scenario. Percentile results of the conventional container should be compared to the same percentile in each of the lightweighting scenarios, and so it is confirmed that a reduction in energy demand does occur no matter the level of uncertainty selected. 


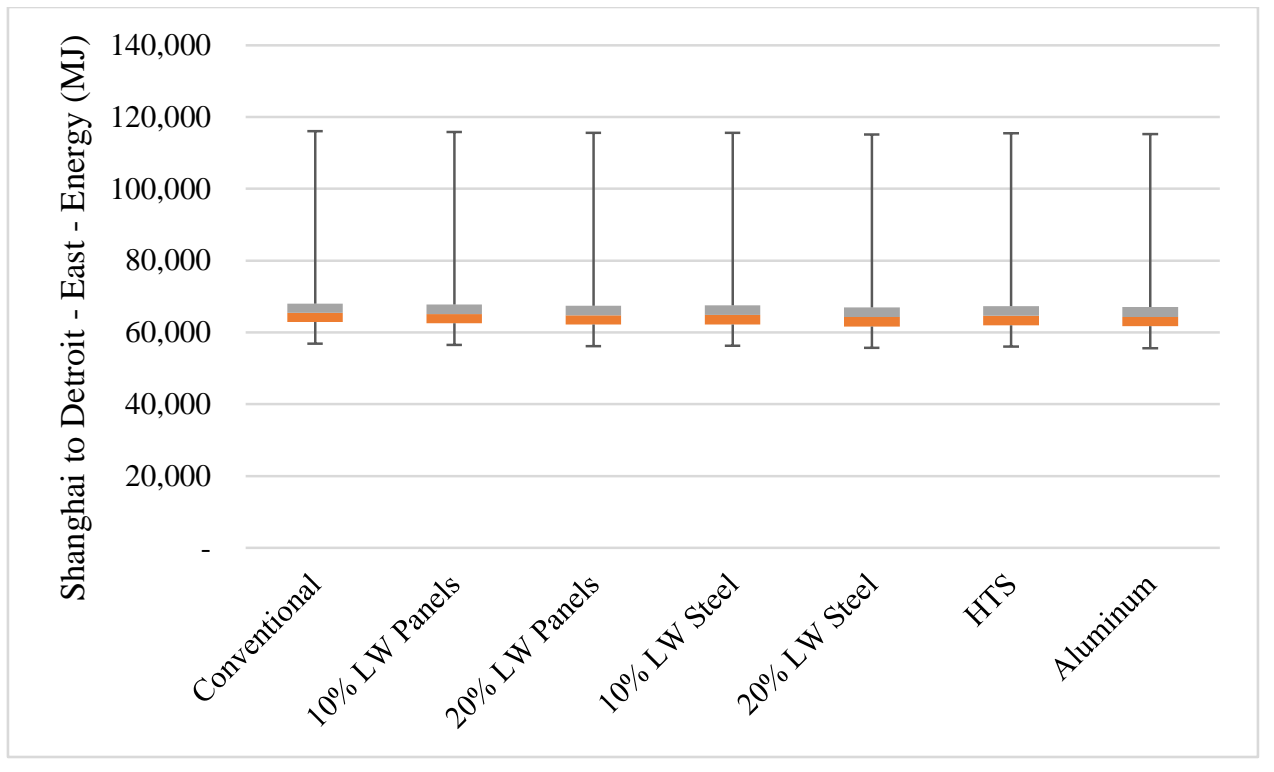

Figure A6 Monte Carlo Shanghai to Detroit (East) Case Study Energy Demand. Monte Carlo results for case study reporting energy required to move containers from Shanghai to Detroit, Michigan, through the Panama Canal. The uncertainty results of the different lightweighting scenarios should be compared to each other by percentile.

\section{Rotterdam to Pittsburgh}

For the second case study, a trip from Rotterdam to Pittsburgh was used to analyze the impact of backhauling. In the subcase in which no backhauling occurred, there was variation in each of the inputs listed in Table A3 as well as in truck distance (minimum: $579 \mathrm{~km}$, most likely: $579 \mathrm{~km}$, and maximum: $602 \mathrm{~km}$ ) and ship distance (minimum: 6,186 km, most likely: 6,186 $\mathrm{km}$, and maximum: 6,960 km). Figure A7 demonstrates the results of the Monte Carlo simulation conducted for the energy demand. Similarly to the previous case study uncertainty results, there exists a large amount of uncertainty as evidenced by the large upper quartile. Once again, it is postulated that this is due to the variation inherent in so many input variables. The inner two quartiles provide a more realistic representation of the uncertainty, indicating that the energy demand for a conventional container being transported from Rotterdam to Pittsburgh will range from 28,300 MJ to 30,400 MJ. This range falls for lightweighting scenarios, with the container lightweighted with aluminum requiring 27,900 MJ to 29,900 MJ. 
Despite the range in results caused by the uncertainty of the inputs, there is a reduction in burdens achieved by lightweighting. The results of a conventional container at a particular percentile should be compared to the associated percentile in any of the lightweighting scenarios.

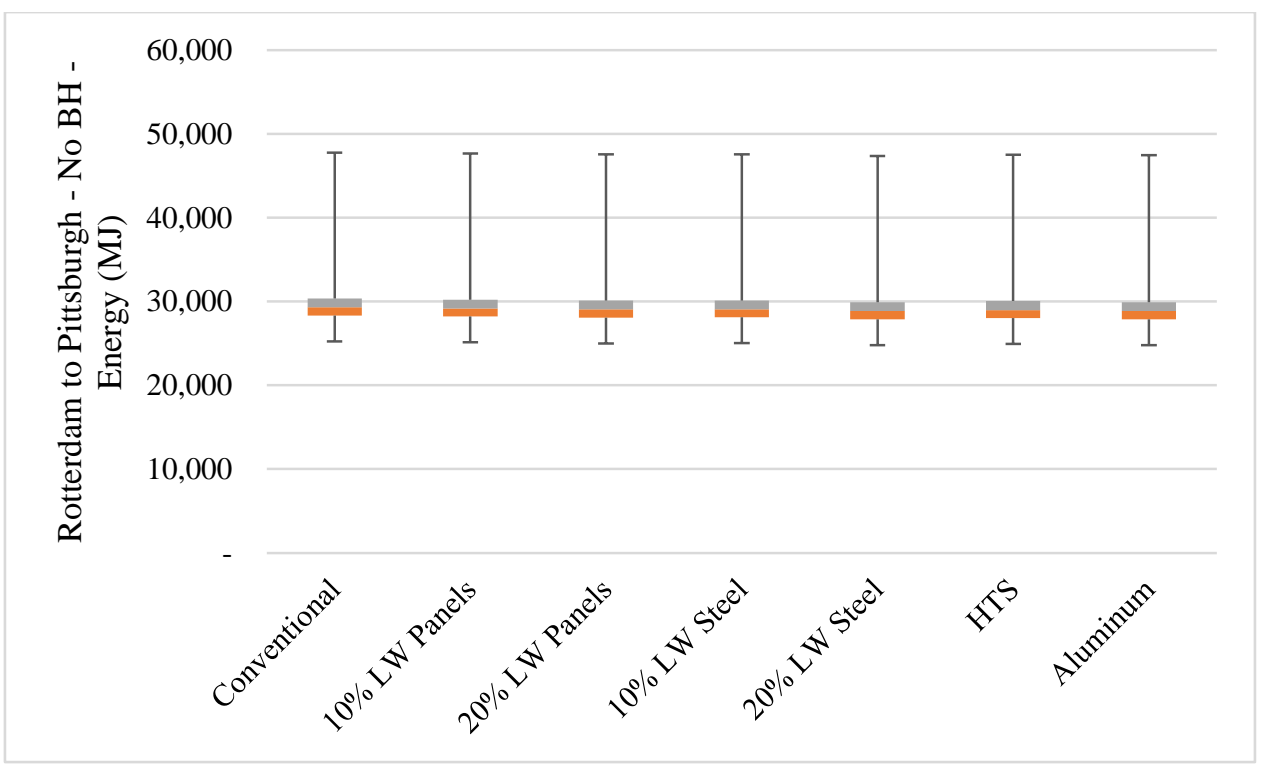

Figure A7 Monte Carlo Rotterdam to Pittsburgh (No Backhauling) Case Study Energy Demand. Monte Carlo results for case study reporting energy required to move containers from Rotterdam to Pittsburgh, Pennsylvania. The uncertainty results of the different lightweighting scenarios should be compared to each other by percentile.

Figure A8 indicates the Monte Carlo sensitivity results for the case in which backhauling was included in the model after a container was transported from Rotterdam to Pittsburgh. The uncertainty in input variables include those listed in Table A3, and in the truck and ship distances listed for the original trip from Rotterdam to Pittsburgh described previously. In addition, there was uncertainty in the truck distance (minimum: $399 \mathrm{~km}$, most likely: $399 \mathrm{~km}$, maximum: $442 \mathrm{~km}$ ) and ship distance (minimum: 6,510 km, most likely: 6,630 km, maximum: 7,206 km) traveled during the return trip to Rotterdam. The results in Figure A8 once again depict large uncertainty due to the combination of so much uncertainty in the input variables. 
The inner two quartiles are relatively small, however, indicating that they are more representative of the actual uncertainty than large upper tail. It is clear that the $50 \%$ of the values calculated for energy demand for the conventional container will range between 55,000 MJ and 58,800 MJ, which drops to 54,100 MJ-58,000 MJ for the aluminum lightweighting scenario. Similarly to previous cases, the uncertainty results should be compared so that the percentiles are consistent between the conventional and lightweighting cases.

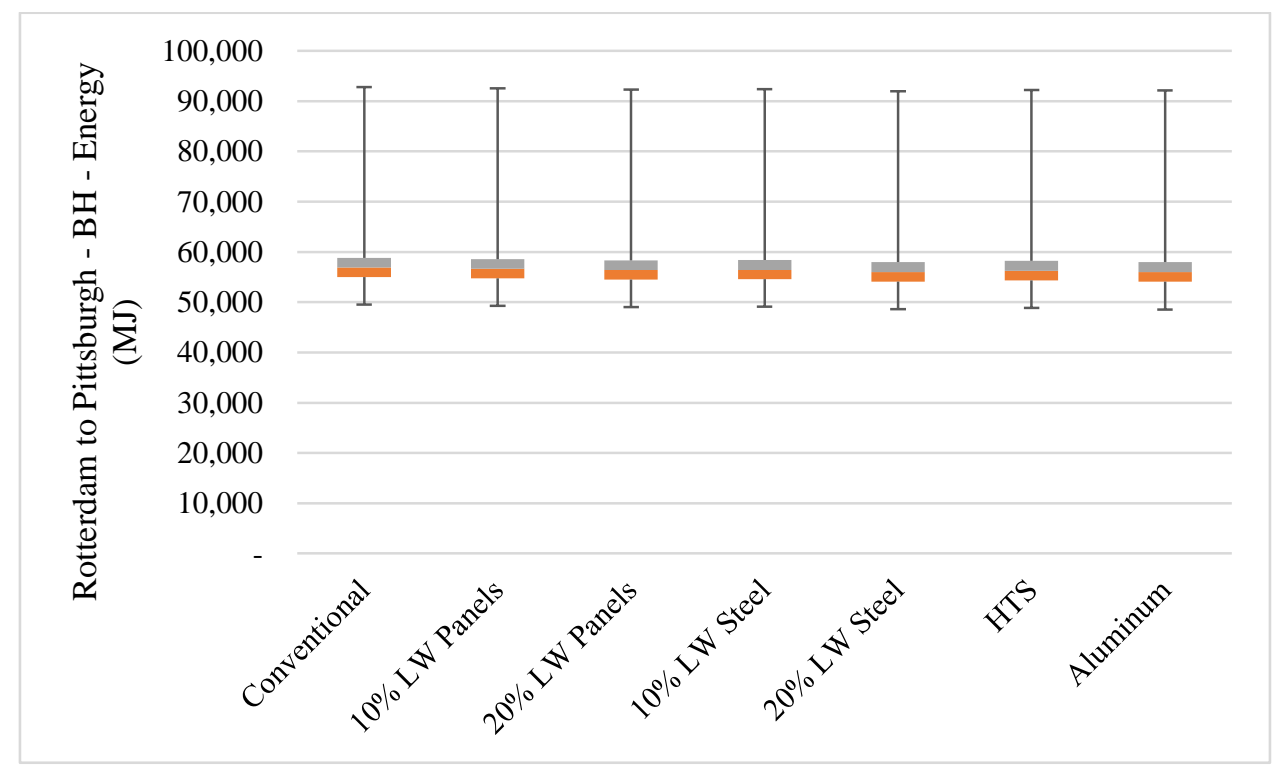

Figure A8 Monte Carlo Rotterdam to Pittsburgh (Backhauling) Case Study Energy Demand. Monte Carlo results for case study reporting energy required to move containers from Rotterdam to Pittsburgh, Pennsylvania, and then backhauled to Rotterdam. The uncertainty results of the different lightweighting scenarios should be compared to each other by percentile. 